\title{
Biological Management of Vascular Wilt of Chickpea (Cicer arietinum L.) Incited by Fusarium oxysporum $f$. sp. ciceris by Antagonistic Rhizobacteria Co-Inoculated with Native Mesorhizobium
}

\author{
Suman Kumari* and Veena Khanna \\ Department of Microbiology, Punjab Agricultural University, Ludhiana-141004, \\ Punjab, India \\ *Corresponding author
}

\section{A B S T R A C T}

\begin{abstract}
Keywords
Chickpea,

Rhizobacteria,

Mesorhizobium,

Fusarium wilt,

Biocontrol,

Phytopathogen

Article Info

Accepted:

10 December 2017

Available Online:

10 January 2018

Sixty one out of 200 isolates, isolated from chickpea rhizospheric soils, were found to be effective to control the mycelial proliferation of the test pathogen Fusarium oxysporum $f$. sp. ciceris, maximum being with Ps16b (45.7\%) and Ps45 (87.3\%) in dual culture plate and liquid broth assay. Growth inhibition of the phytopathogen was also recorded by diffusible and volatile antifungal metabolites produced by the isolates. All the isolates showed ammonia production, whereas only nine isolates were recorded for Hydrogen cyanide production. Five potent antagonists (Ba1a, Ba19, Ps44, Ps45 and Ps47), selected on the basis of antagonistic traits were evaluated under greenhouse conditions to control fusarium wilt in chickpea varieties GPF-2 and JG-41. Maximum reduction in disease incidence was recorded with Ps45 $(74.48 \pm 0.67 \%)$ and $(70.32 \pm 1.00 \%)$ compared to fungicide treatment $(61.53 \pm 0.89 \%$ and $58.69 \pm 0.33 \%)$ in chickpea genotypes GPF-2 and JG-41 respectively. Rhizobacterial isolates Ps45, Ps47 and Ba1a inoculation alongside Mesorhizobium were found effective in promoting seed emergence and in controlling the disease severity.
\end{abstract}

\section{Introduction}

Chickpea (Cicer arietinum L.) is an important pulse crop and accounts for $48 \%$ of the total pulse production in India (Anonymous, 2015). This crop is widely attacked by soil-borne diseases resulting in severe yield losses and one of them is fusarium wilt incited by Fusarium oxysporum f. sp. ciceris (Foc, Padwick) which is a serious soil borne disease of chickpea (Hossain et al., 2013; Merkuz et al., 2011). It is a major constraint to chickpea cultivation throughout the world and especially in Indian subcontinent where chickpea is a commonly grown pulse crop, as it can cause up to $100 \%$ yield loss annually (Pande et al., 2010; Kumari and Khanna, 2014). This disease can affect the crop at any stage of growth. Characteristic symptoms are sudden drooping of leaves and petioles and black internal discoloration involving xylem and pith (Dubey and Singh, 2004).

Management of fusarium wilt is not a simple assignment, as no single control measure is fully effective (Butler, 1981). Several 
measures including crop rotation or application of chemicals are there, but it is difficult to manage fusarium wilt by either of these, because of soil nature persistence and its capacity to survive for long time even in the absence of host (Moradi et al., 2012). Thus, the use of fungicides is not usually effective as it is used mainly for the seed borne inoculum and the effect is short lived (Merkuz et al., 2011). The disease can also be managed using resistant cultivars, but resistant varieties are neither available nor can be effective against different races of the pathogen prevalent in the country (Merkuz and Getachew, 2012). As a result, an alternative to the use of synthetic pesticides with the advantages of greater public acceptance and reduced environmental impact is required (Reino et al., 2008).

Biological control using microbes is becoming a critically needed component of plant disease management, particularly in reducing root diseases (Nautiyal, 2000; Meki et al., 2009). At present, biological control of soil and seedborne plant pathogenic fungi has been addressed mainly by using bacterial and fungal antagonists. Strains of Trichoderma spp. and non-pathogenic isolates of $F$. oxysporum and some rhizobacteria especially Pseudomonas spp. and Bacillus spp., isolated from the rhizospheres of crop plants, are reported to be effective not only to control plant pathogens but also help the plants to mobilize and acquire nutrients (Gopalakrishnan et al., 2011). Moreover the use of biocontrol agents is much safer and is presumed to be less polluting to the environment than the chemical pesticides (Sumeet and Mukerji, 2000).

Various mechanisms for antagonism have been implicated, like cell wall degrading enzymes (pectolytic enzymes, cellulases, xylanases and glycosidic hydrolases), siderophores that can chelate iron and other metals and contribute to disease suppression by conferring a competitive advantage to the biocontrol agent for the limited supply of essential trace minerals in natural habitats (Deshwal et al., 2003). Kravchenko et al., (2002) reported that microbial siderophore may also stimulate plant growth directly by competitively inhibiting iron uptake system by fungal pathogen. Biocontrol agents also produce various types of volatile and diffusible antifungal metabolites and antibiotics, capable of reducing or suppressing infection by pathogenic fungi in several pathosystems (Yang et al., 2009). Furthermore, rhizobacteria have received particular attention because of their excellent root colonizing ability and their ability to induce plant's defence mechanism via production of various pathogenesis related proteins (Kumar et al., 2010).

This research was carried out as an alternative strategy to chemical control, with the objective of evaluating the potential of rhizobacterial isolates from chickpea rhizosphere for controlling chickpea fusarium wilt. For this, the most promising rhizobacterial antagonists of Foc, were isolated and screened for in vitro trials. Selected potential antagonists were further evaluated for their ability to reduce fusarium wilt symptoms and to enhance the seedling emergence under greenhouse conditions.

\section{Materials and Methods}

\section{Collection of soil samples, isolation, purification and identification of rhizobacterial isolates}

Soil samples were collected randomly from different locations. Samples were collected in sterile plastic bags. From each sample, $10 \mathrm{~g}$ of soil was added to $90 \mathrm{ml}$ of distilled sterilized water and vigorously shaken using a shaker for 20-30 minutes. From this, seven fold serial 
dilutions were made by pipetting $10 \mathrm{ml}$ into additional dilution water. From the final dilution $\left(10^{-7}\right)$, aliquots of $0.1 \mathrm{ml}$ each were spread on plates, containing $20 \mathrm{ml}$ of Nutrient agar for Bacillus and Serratia spp. and King's $\mathrm{B}$ or Pigment producing medium (PsP) for Pseudomonas spp. (King et al., 1954) and incubated at $25{ }^{\circ} \mathrm{C}$ for 24 hours.

Bacterial colonies developed on respective media, were picked and transferred to respective slants for further use. Initial characterization of all the isolates was done on the basis of colony morphology and gram's staining. Biochemical characterization of bacterial isolates was done as per the standard methods (Cappuccino and Sherman, 1992).

\section{Pathogen culture}

The fungal pathogen Fusarium oxysporum $\mathrm{f}$. sp. Ciceris, procured from the Department of Plant Breeding and genetics, Punjab Agricultural University was maintained on Potato Dextrose agar slants.

Assessment of antiphytopathogenic activity of rhizobacterial isolates against the root phytopathogen

In vitro testing of rhizobacteria against mycelial growth of Fusarium oxysporum $f$. sp. ciceris (Dual culture agar plate assay)

The antagonistic rhizobacterial isolates were screened by dual culture plate assay as per the the method described by Ahmed Idris et al., (2007). Ten $\mu 1$ drops from the $10^{8} \mathrm{cfu} / \mathrm{ml}$ bacterial broth suspension were placed on the margin $(2 \mathrm{~cm}$ away from the fungal disc) of potato dextrose agar (PDA) plates and a $5 \mathrm{~mm}$ agar disc from fresh cultures of pathogenic fungi was placed at the centre of the PDA plate for each bacterial isolate and incubated at $25 \pm 3{ }^{\circ} \mathrm{C}$ for seven days. The radial growth of the fungal colony towards and away from the bacterial colony was measured. The percentage growth inhibition was calculated using the following formula:

$\%$ Inhibition $=(\mathrm{R}-\mathrm{r}) / \mathrm{R} \times 100$

Where, $\mathrm{r}$ is the radius of the fungal colony opposite the bacterial colony and, $\mathrm{R}$ is the maximum radius of the fungal colony away from the bacterial colony. There were three replicate in this assay.

\section{Fungal biomass inhibition in liquid medium (Liquid antibiosis)}

One $\mathrm{ml}$ of $24 \mathrm{~h}$ old fresh bacterial culture and a disc of test fungus $(5 \mathrm{~mm})$ from a wellgrown fungal colony on PDA plates were inoculated in $50 \mathrm{ml}$ broth of sterile potato dextrose media in $250 \mathrm{ml}$ conical flasks at $25^{\circ} \mathrm{C}$. Broth inoculated only with pathogen fungus served as control. The differences in dry weights of fungal mycelium treated with bacterium and the control cultures were recorded after 5 days through preweighed filter paper (Whatmann No.1). The filter papers were dried for $24 \mathrm{~h}$ at $70^{\circ} \mathrm{C}$ and weighed. The percent reduction in weight of the test fungus was calculated using formula:

$\%$ Reduction in weight $=(\mathrm{w} 1-\mathrm{w} 2) / \mathrm{w} 1 \times 100$

Where, w1 represents the weight of the test fungus in control flasks and w2 with the bacterial antagonists.

Growth inhibition by production of Diffusible antimetabolites (covered membrane method)

PDA plates covered with a cellophane membrane were overlaid with nutrient agar and inoculated with $100 \mu \mathrm{l}$ of antagonistic bacterial suspension. After incubation for 48 hrs at $28^{\circ} \mathrm{C}$, the membrane along with the grown bacterial isolate was removed and the 
plate was inoculated in the middle with $10 \mathrm{~mm}$ disc of a pure culture of $F$. oxysporum. Plates were incubated at $22^{\circ} \mathrm{C}$ for $48 \mathrm{hrs}$ and the growth of the pathogen was measured (Kumari and Khanna, 2014).

\section{Antagonistic activity via volatile antifungal} compounds (sealed plate method)

One hundred $\mu$ of fresh prepared broth culture was spread on nutrient agar medium plate.

A second petri dish containing PDA was inoculated with a 6-mm bit of the test fungus and placed over the bacterial culture. The two plates were sealed together with parafilm and further incubated at $25^{\circ} \mathrm{C}$. As a control, a petri plate containing nutrient agar medium without bacteria was placed over the PDA medium inoculated with the fungal pathogen. Radial growth of the test fungus was observed over 24 hour intervals for 5 days.

\section{Hydrogen Cyanide (HCN) production}

Petri plates containing $10 \%$ Trypticase soya agar supplemented with $4.4 \mathrm{~g}$ of glycine per litre were spread with $0.1 \mu \mathrm{l}$ of $24 \mathrm{hrs}$ old bacterial cultures. The plates were inverted with a lid containing filter paper, impregnated with $0.5 \%$ picric acid and $2 \%$ sodium carbonate. The plates were incubated at $28^{\circ} \mathrm{C}$ for 3 to 5 days. A change in colour from yellow to orange-brown on the filter paper indicated cyanide production (Bakker and Schippers, 1987).

\section{Production of ammonia}

Fresh ( 24 hrs) grown cultures were inoculated in $10 \mathrm{ml}$ peptone water and incubated for 48 72 hours at $30^{\circ} \mathrm{C}$. Nessler's reagent $(0.5 \mathrm{ml})$ was added in each test tube. Development of brown to yellow colour was a positive test for ammonia production (Cappuccino and Sherman, 1992).
Evaluation of plant growth promoting potential by potent antagonists

Selected antagonists were further evaluated for their potential to enhance the growth of the plants via production of phytohormones and iron chelating agents in vitro conditions. Indole acetic acid production in Luria broth by the antagonistic isolates, was performed with Van Urk Salkowski reagent using the Salkowski's method (Ehmann, 1977). The Gibberellic acid production by was determined by Borrow et al., method (Borrow et al., 1995). Siderophore production was detected on Chrome azurol sulphonate agar plate test (Schwyn and Neilands, 1987). Selected bacterial strains were tested by an agar assay using National Botanical Research Institute's phosphate (NBRIP) medium for phosphate solublization (Edi Premono et al., 1996). The isolates were inoculated into minimal agar medium containing $0.1 \%$ insoluble zinc oxide. Twenty four hours fresh grown bacterial isolates were spotted on the Zinc containing medium and incubated at $30^{\circ} \mathrm{C}$ for 48 hours for the clearing zones around the colonies.

Evaluation of antiphytopathogenic potential of antagonistic rhizobacteria under glass house conditions

\section{Chickpea genotypes}

Seeds of two chickpea genotypes "GPF-2 and JG-41" were selected and procured from Punjab Agricultural University.

\section{Bacterial cultures and seed bacterization}

Selected rhizobacterial cultures were inoculated @ 1\% in $100 \mathrm{ml}$ of nutrient broth and were incubated at for 24 hours with bacterial count of $10^{7-8} \mathrm{cfu} / \mathrm{ml}$ of the broth. The seeds of GPF-2 and JG-41 chickpea varieties were washed with $0.1 \%$ Mercuric 
chloride followed by $70 \%$ ethanol and then repeatedly with sterile distilled water for surface sterilization. After that, seeds were soaked in selected five bacterial broth cultures

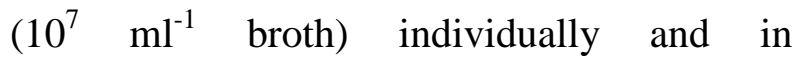
combination with native Mesohizobium ciceri, procured from department of Microbiology, Punjab Agricultural University (1:1) for 20-30 minutes before sowing the seeds.

\section{Pathogen culture multiplication and soil inoculation}

Fusarium oxysporum f. sp. ciceris was mass multiplied in Potato dextrose broth. Mycelial mat was used to inoculate pathogen in soil i.e. $10 \mathrm{~g} / \mathrm{Kg}$ of the soil. Soil was mixed thoroughly to disperse fungal hyphae and spores properly in the soil.

\section{Preparation for pot experiment}

Selected antagonists and their co-inoculation with Mesorhizobium were examined for their potential to reduce wilt incidence under the glass house conditions, using sterile soil inoculated with pathogen. The experiment was designed with 13 treatments, with 5 selected culture treatments alone and in combination with Mesorhizobium (1:1). The absolute control with pathogen free soil and untreated seeds, negative control with sick soil and untreated seeds and Fungicide treatment with sick soil and captan treated seeds $(2 \mathrm{~g} / \mathrm{Kg}$ seeds) were also maintained as separate treatments. Soil collected from chickpea field was autoclaved at $15 \mathrm{lbs}\left(121^{\mathrm{C}} \mathrm{C}\right)$ for 15 minutes for sterilization. Polyethylene bags $(15 \times 10 \mathrm{~cm})$ were filled with $250 \mathrm{~g}$ sterilized soil inoculated with pathogen mycelial mat i.e. $10 \mathrm{~g} / \mathrm{Kg}$ soil. Ten seeds were sown in each pot. Pots were maintained by regular watering upto maturity and were examined for seedling emergence during initial 5-10 days. Wilt incidence was recorded up to maturity of crop plants and reduction in disease severity was recorded as: \% wilt in particular treatment - \% wilt in negative control $/ \%$ wilt in negative control $\times 100$.

Data were statistically tested by analysis of variance (ANOVA) using CPCS1 software developed by Department of Mathematics, Statistics and Physics, PAU. Each treatment was analyzed with three replicates and standard error (SE) was calculated and data are expressed in mean $\pm \mathrm{SE}$ of three replicates.

\section{Results and Discussion}

Two hundred rhizobacterial isolates, isolated from chickpea rhizospheric soil samples collected from different locations of Punjab, Haryana and Uttar Pradesh, were screened on the basis of antagonism test (dual culture) plates where confluent bacterial growth inhibited fungal mycelial development. Sixty one isolates were found to show inhibitory effect on the growth of the fungal pathogen.

Selected antagonists were assessed for morphological and biochemical characteristics as per Bergey's manual of Systemic Bacteriology. Twenty three isolates were found to be Gram positive and thirty eight were characterized as Gram Negative by Gram staining. Morphologically, all the isolates were found to be rod shaped. Bacterial cultures isolated on Kings $\mathrm{B}$ medium produced fluorescent green to blue green coloured colonies (Plate 1). Two of the isolates on Nutrient agar were observed with red coloured colonies. Selected cultures were tested for starch hydrolysis, catalase production, Methyl red test, Citrate test and Nitrate production test. On the basis of morphological and biochemical characterization, 23 cultures were observed to belong to Bacillus spp., 36 to Pseudomonas and 2 to Serratia spp. Bacterial cultures were maintained on Nutrient agar slants and were stored at low temperature i.e. $4^{\circ} \mathrm{C}$. 


\section{Dual culture agar plate assay}

Out of 200 isolates, sixty one isolates were effective in reducing mycelial growth of the pathogen. The results revealed that the PGPR strains inhibited the growth of Fusarium oxysporum f. sp. Ciceris (Foc) to a varying extent, $25.7 \pm 1.22$ to $45.7 \pm 3.58 \%$. Somewhat similar range was recorded in our earlier case study where antagonistic rhizobacterial inhibition of Foc radial growth was observed between 18.2- 41.8\% (Kumari and Khanna, 2014). The application of Ps16b recorded the maximum inhibition i.e. followed by Ps47, Ps44 and Ps45 (Plate 2). However among the Bacillus isolates, $\mathrm{Ba} 5$ and $\mathrm{Ba} 7$ were recorded with pathogen radial inhibition of $41.4 \%$ followed by Ba1a, Ba15, Ba18, Ba19, Ba27 and Ba36 with $40 \%$ inhibition (Table 1). Observations revealed that Pseudomonas isolates showed more inhibitory effect than the Bacillus or Serratia spp in dual culture plate assay in support to the observations by Altinok et al., 2014 where $P$. aeruginosa (P07-1 and 85A-2) and P. putida (P11-4) inhibited $70 \%$ of the radial growth of Fusarium oxysporum f. sp. melongenae (Fomg). The control was recorded with $7 \mathrm{~cm}$ of growth after 7 days that was referred as standard to calculate the percentage inhibition. Antagonistic activity of rhizobacterial isolates can be due to different diffusible and volatile antifungal metabolites and competitions for various nutrients (Gopalakrishnan et al., 2011).

\section{Liquid broth antibiosis}

The antagonistic rhizobactera were also evaluated for their antipathogenic potential in liquid medium. In this method bacterial inhibitory effect on the mycelial proliferation in terms of dry weigh was recorded. All the isolates showed reduction in fungal biomass in a varied content compared to control. Inhibitory effect on mycelial proliferation varied between $26.4 \pm 0.72$ to $87.3 \pm 0.10 \%$. Ps45 induced maximum inhibition in liquid medium followed by Ps44 and Ba1a (Table 2). However in a similar work Bacillus isolate 2B inhibited the mycelial proliferation up to 93.9\% and Pseudomonas isolates 34P, 28P and $20 \mathrm{P}$ were also recorded with antagonistic effect of 84.4, 79.8 and $79.8 \%$ respectively (Kumari and Khanna, 2014). As the liquid medium provides better interaction between the pathogen and the antagonist, that can be the reason of higher percentage inhibitory effect of bacterial antagonists on fungal growth than in dual culture plate assay. Such an effective antagonistic activity by these rhizobacterial isolates can be an alternate to the various chemical mechanisms to control this pathogen.

\section{Antagonism via diffusible antifungal metabolite}

Certain diffusible antibiotics produced by PGPR include phenazine, pyoluteorin, pyrrolnitrin and cyclic lipopeptides and various enzymes that are mainly responsible for degradation of fusaric asic produced by Fusarium spp. and hence help in reduction of vegetative as well as reproductive growth of these pathogens (Ryan et al., 2008). Inhibition varied in the range of $9.0 \pm 0.34$ to $90.9 \pm 0.06 \%$ due to the production of volatile antimetabolites in membrane plate assay Pseudomonas cultures Ps 44, Ps45 and Ps 46 were found very efficient to reduce the radial growth of test fungus to $100 \%$ as the only growth recorded was the bit of $0.5 \mathrm{~mm}$ that was already placed during the inoculation (Plate 3). However among Bacillus isolates, Ba11 was found to be most efficient in pathogen inhibition i.e. $76.3 \%$ followed by Ba19 (74.5 $\pm 0.21 \%$ ) (Table 3). Studies have reported that Bacillus and Pseudomonas spp. produce extracellular chitinase and laminarinase which could lyse the mycelia of Fusarium solani that can be the main reason 
for antagonistic effect (Isnansetyo et al., 2003, Arias et al., 2009). Furthermore flourescent Pseudomonas species produce extracellular metabolites like Phenazine and Di-acetyl phloroglucinol that are mainly implicated in inhibitory effect on various pathogens associated with plant diseases. In support, Giorgio and his co-workers also have reported that an array of rhizobacteria show a negative effect on the growth of various pathogens such as Botrytis cinerea, Fusarium equiseti, $F$. oxysporum, F. solani, Phytophthora nicotianae, Sclerotinia and Verticilium spp. (Giorgio et al., 2015).

\section{Inhibitory effect by volatile antimetabolites}

Volatile antimicrobial compounds are produced by a number of rhizobacteria that can be implied to control various plant pathogens especially that incite the plants in ealier or later stages of plants (Abdeljalil et al., 2016). All the twenty six antagonists variably inhibited Foc radial growth. Isolate
Ps47 induced maximum inhibition (90.7\%) via the production of volatile metabolites. Bacillus isolate $\mathrm{Ba} 27$ inhibited radial growth with $61.5 \%$ following Ps47 (Plate 4). Fiddman and Rossal (1993) revealed that volatiles produced by Bacillus spp. induce profound adversial effect on the mycelial proliferation of various fungal plant pathogens. Isolates $\mathrm{Ba} 1 \mathrm{a}, \mathrm{Ba} 7$, Ba8, Ba11, Ba19, Ps5, Ps11, Ps15, Ps44 and Ps45 were also recorded to inhibit $\geq 50 \%$ of the mycelial growth in sealed plate assay (Table 4). Six out of ten antagonists were found to inhibit Fusarium oxysporum f. sp lycopersici to control wilt in tomato plants with an average percentage inhibition of $31.21 \%$ (Prashar et al., 2013). Some of the species of Serratia, Pseudomonas and Bacillus synthesize and emit complex blends of volatile compounds such as ammonia and hydrogen cyanide that inhibit growth of many phytopathogenic and non phytopathogenic fungi and play an important role in biological control (Kai et al., 2007; Vespermann et al., 2007).

Plate.1 Isolated hizobacteria from chickpea rhizospheric soil on
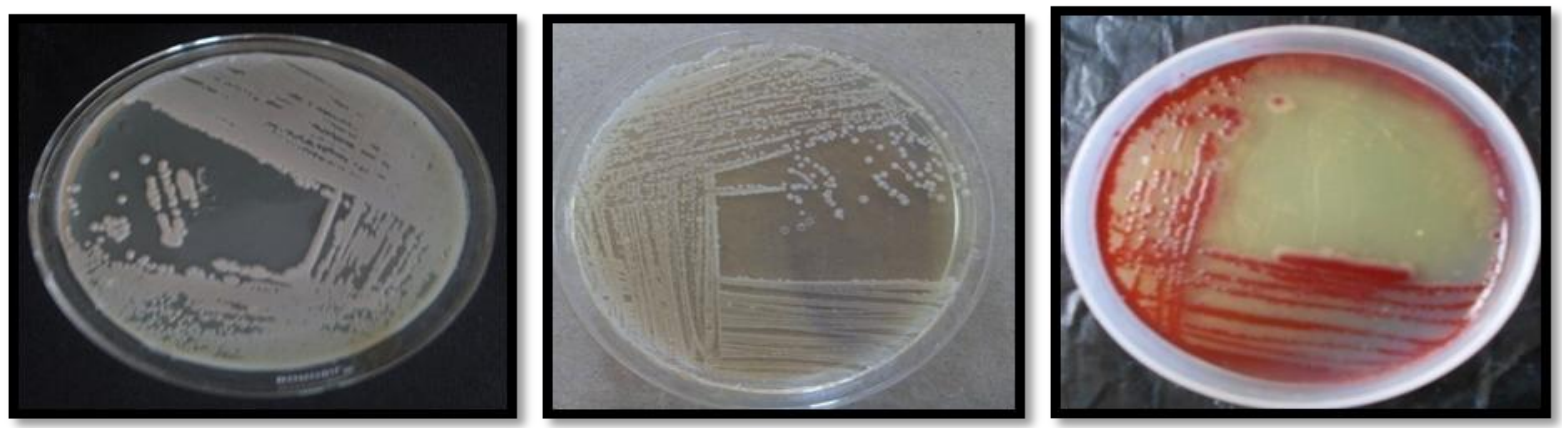

(a) Nutrient agar medium
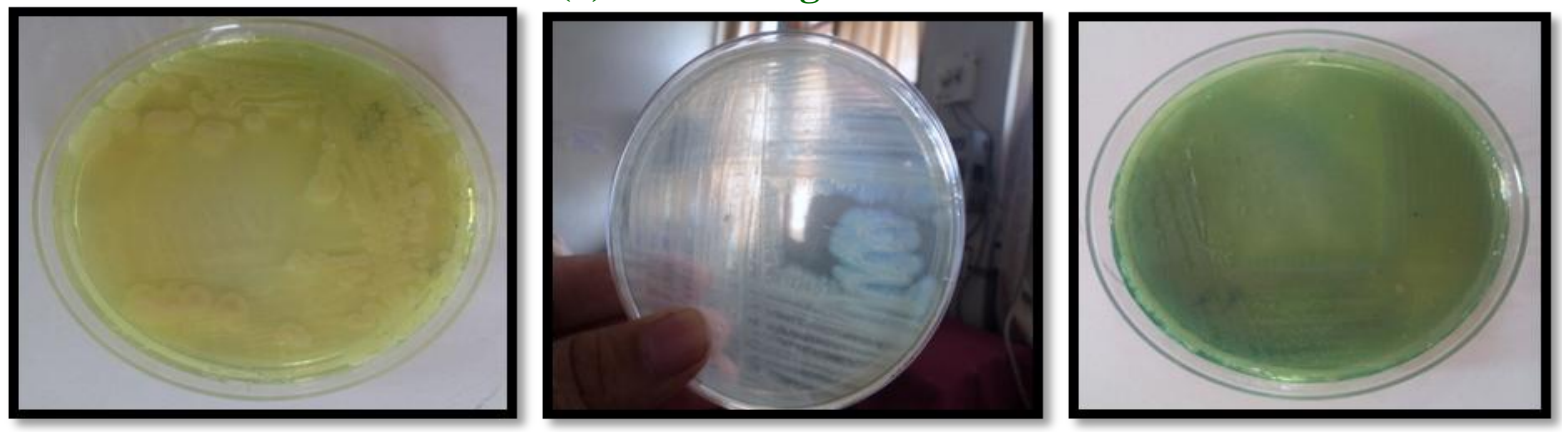

(a)

King's B medium 
Plate.2 Inhibition zone produced by rhizobacterial isolates against Fusarium oxysporum f. sp. ciceris

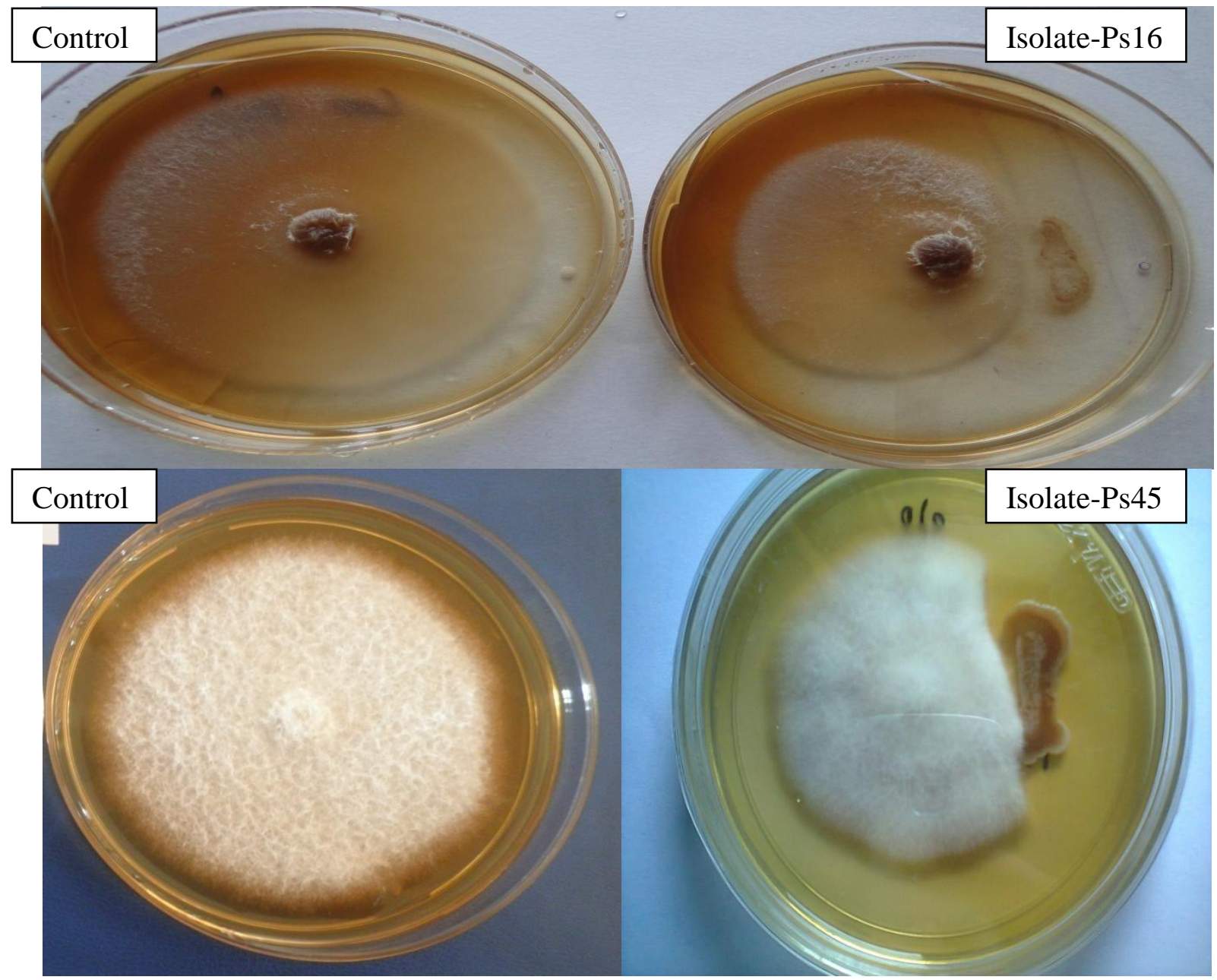

Plate.3 Relative radial growth inhibition of Fusarium oxysporum f. sp. ciceris by rhizobacterial diffusible antimetabolites

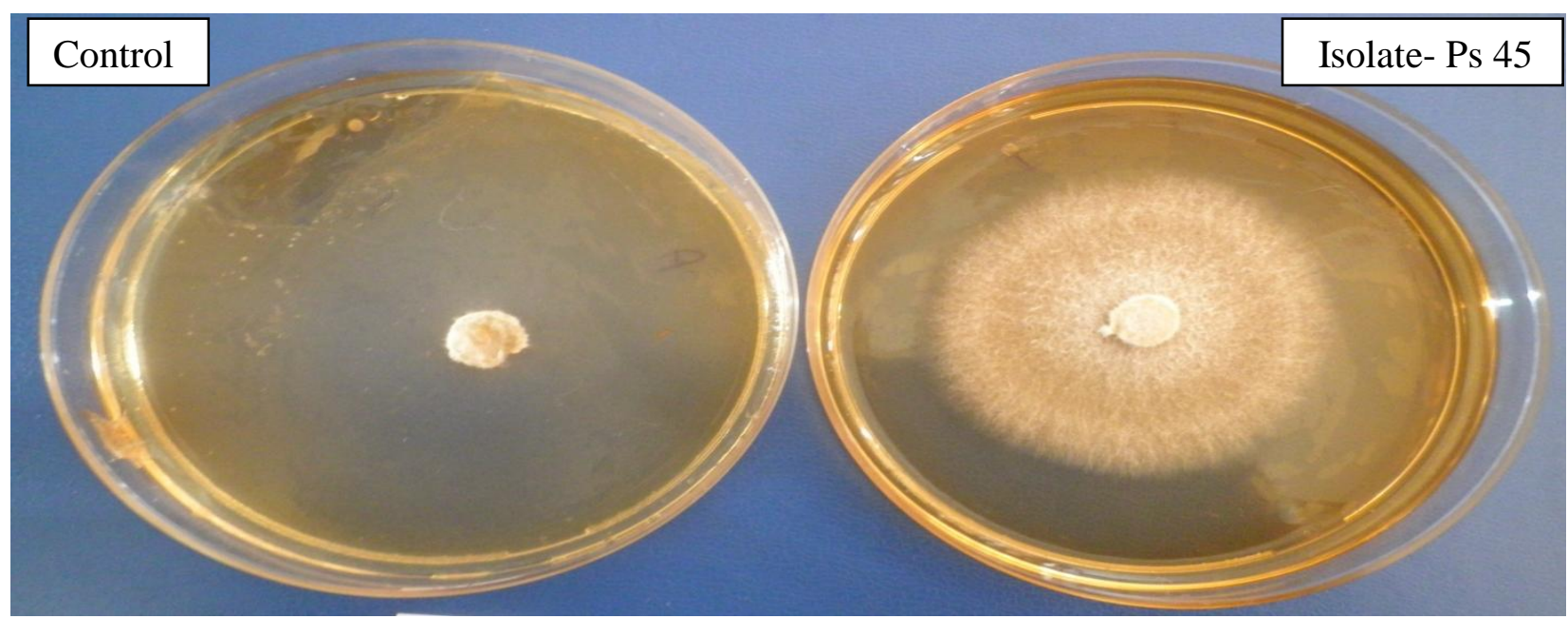


Plate.4 Relative radial growth inhibition of Fusarium oxysporum f. sp. ciceris by rhizobacterial volatiles

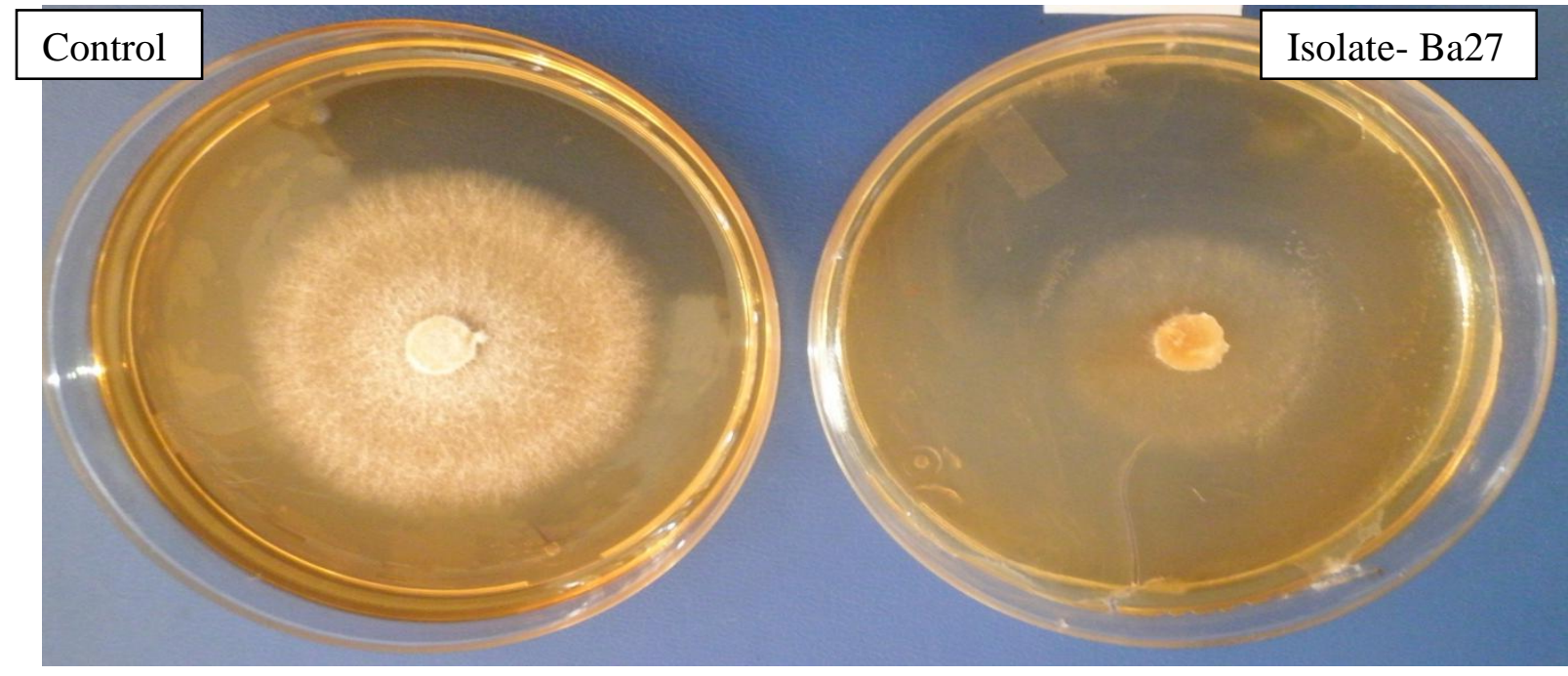

Plate.5 Ammonia production by antagonistic rhizobacteria

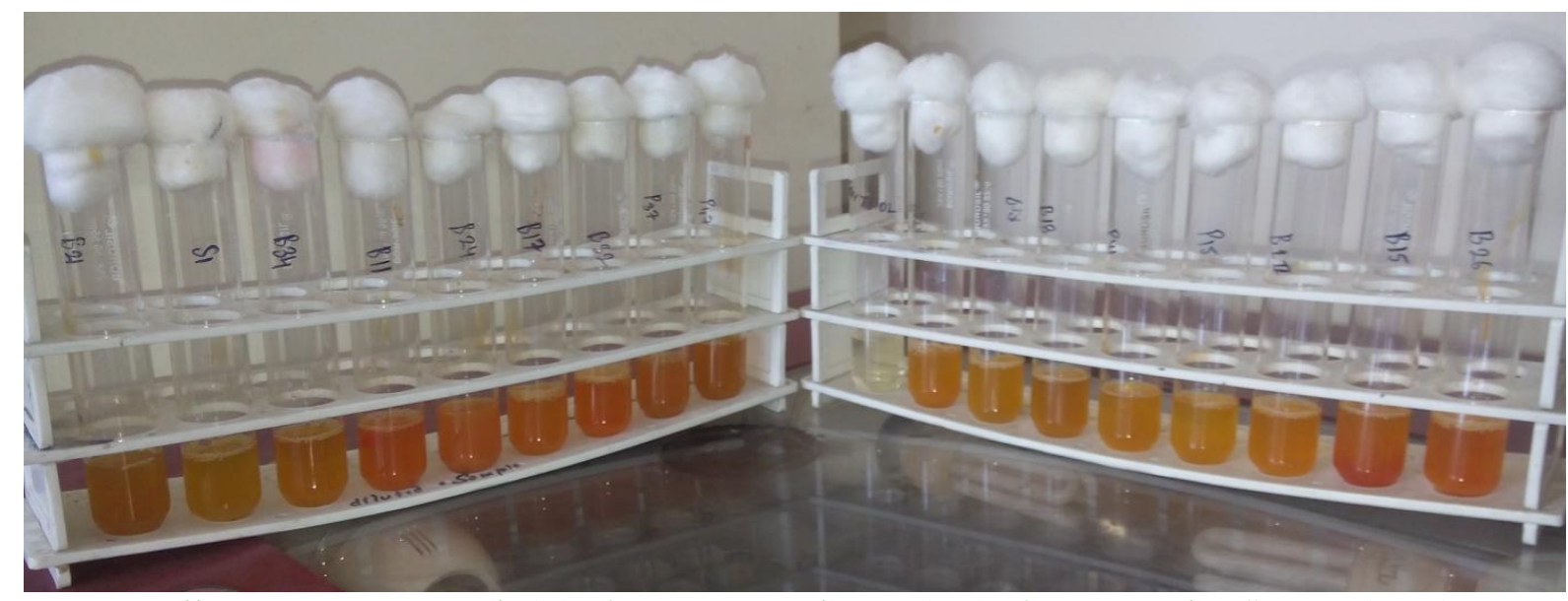

Yellow orange $=$ Weak $(+)$, Orange $=$ Moderate $(++)$, Orange red $=$ Strong $(+++)$

Plate.6 Hydrogen cyanide production by rhizobacterial isolates

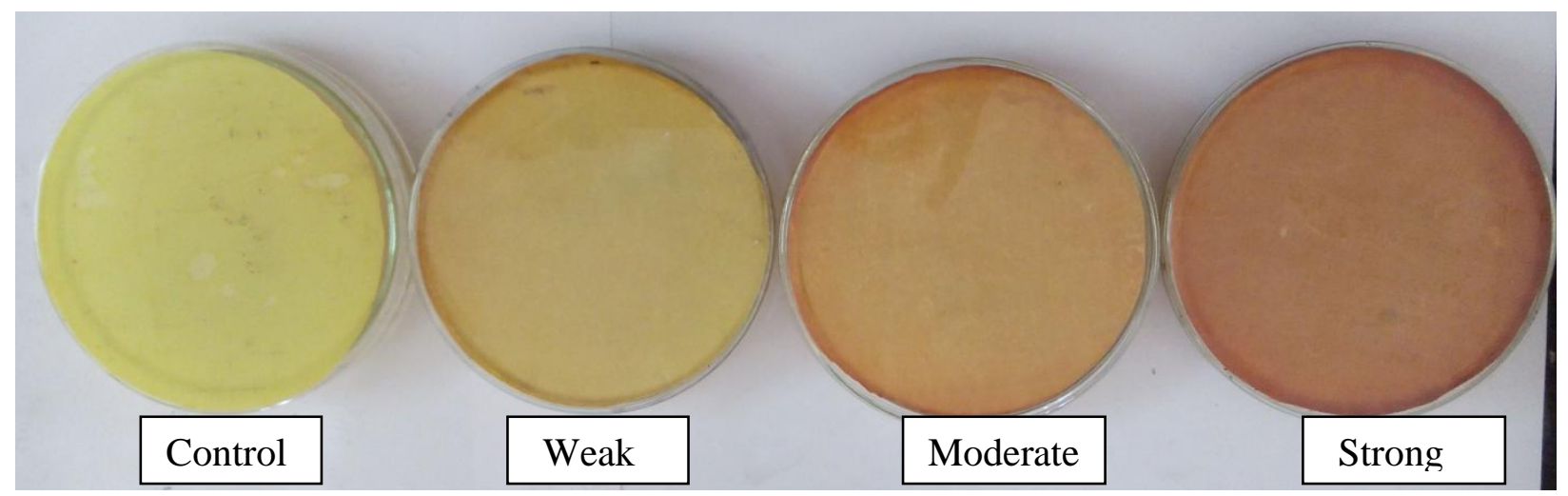


Plate.7 Plant growth promoting characteriatics of selected anatagonists

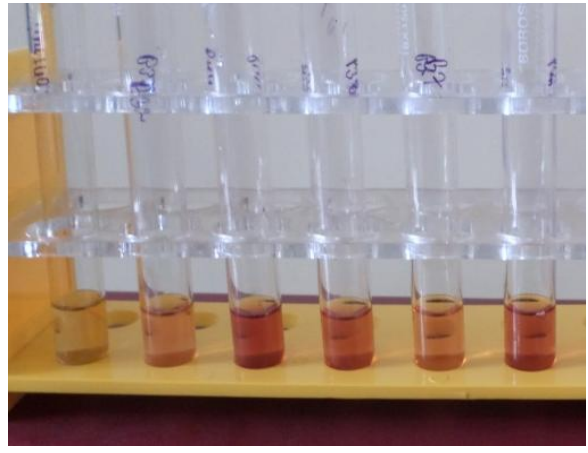

Indole acetic acid production

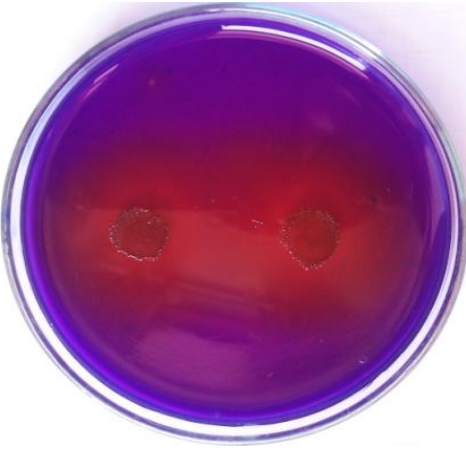

Phosphate solublization

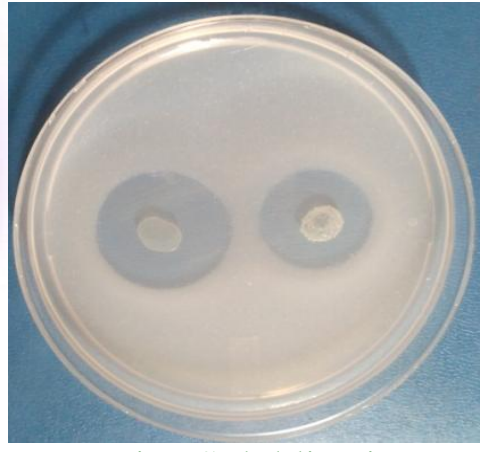

Zinc Solublization

Plate.8 Pot experiment conducted to evaluate the potential of antagonistic rhizobacteria to control wilt, under glass house conditions

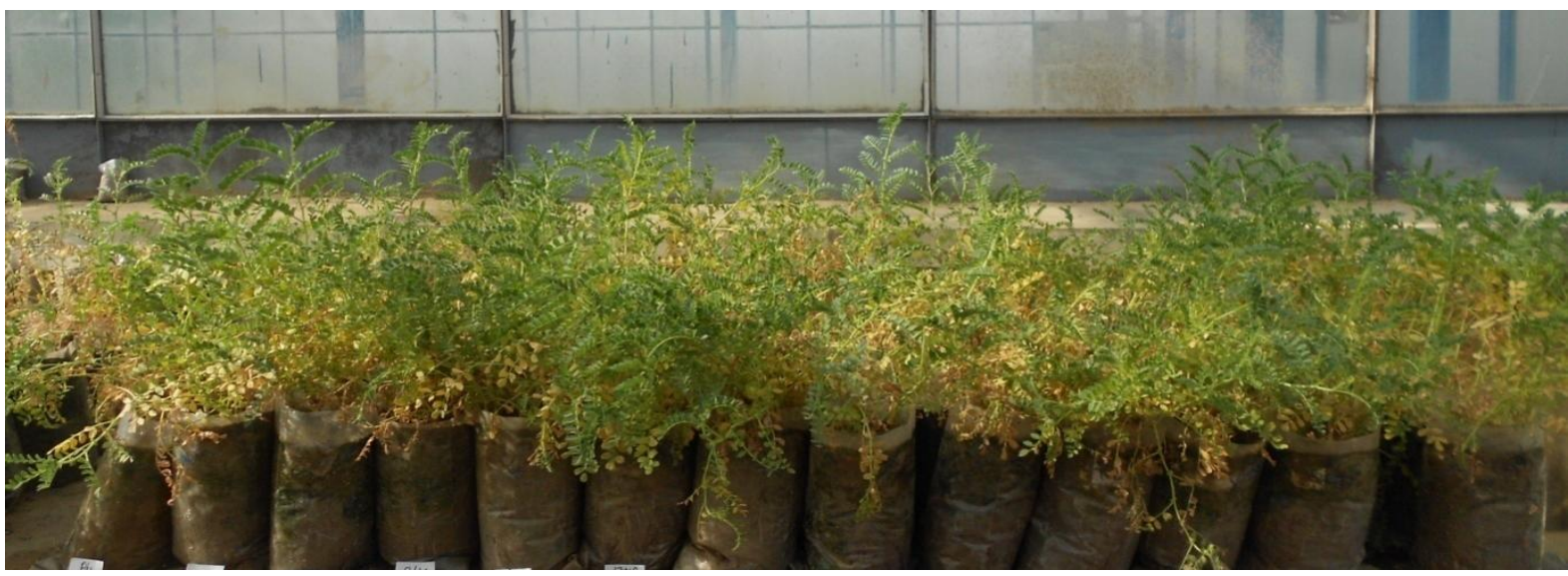

Plate.9 Relative seedling emergence in different treatments in chickpea under glass house conditions (GPF-2)

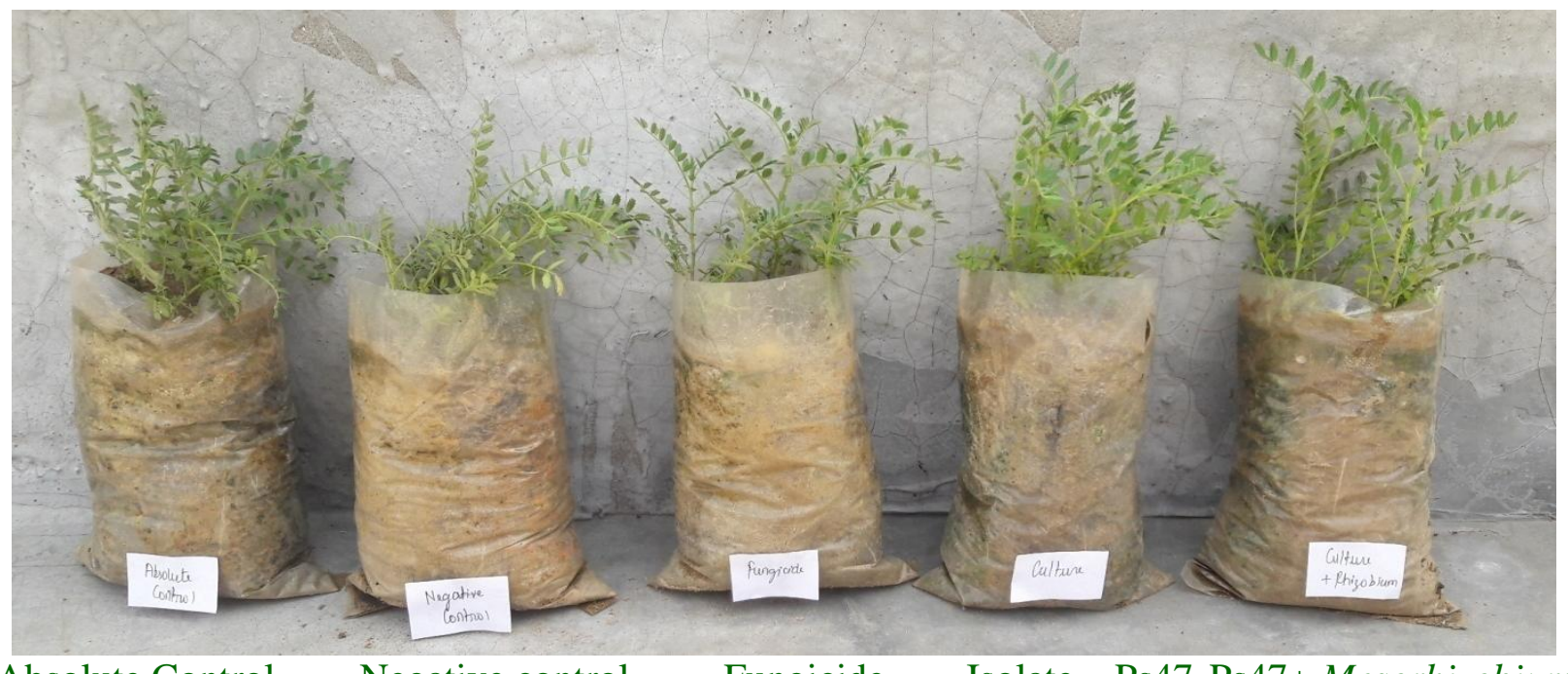

Absolute Control Negative control Fungicide Isolate - Ps47 Ps47+Mesorhizobium 
Plate.10 Relative seedling emergence in different treatments in chickpea under glass house conditions (JG-41)

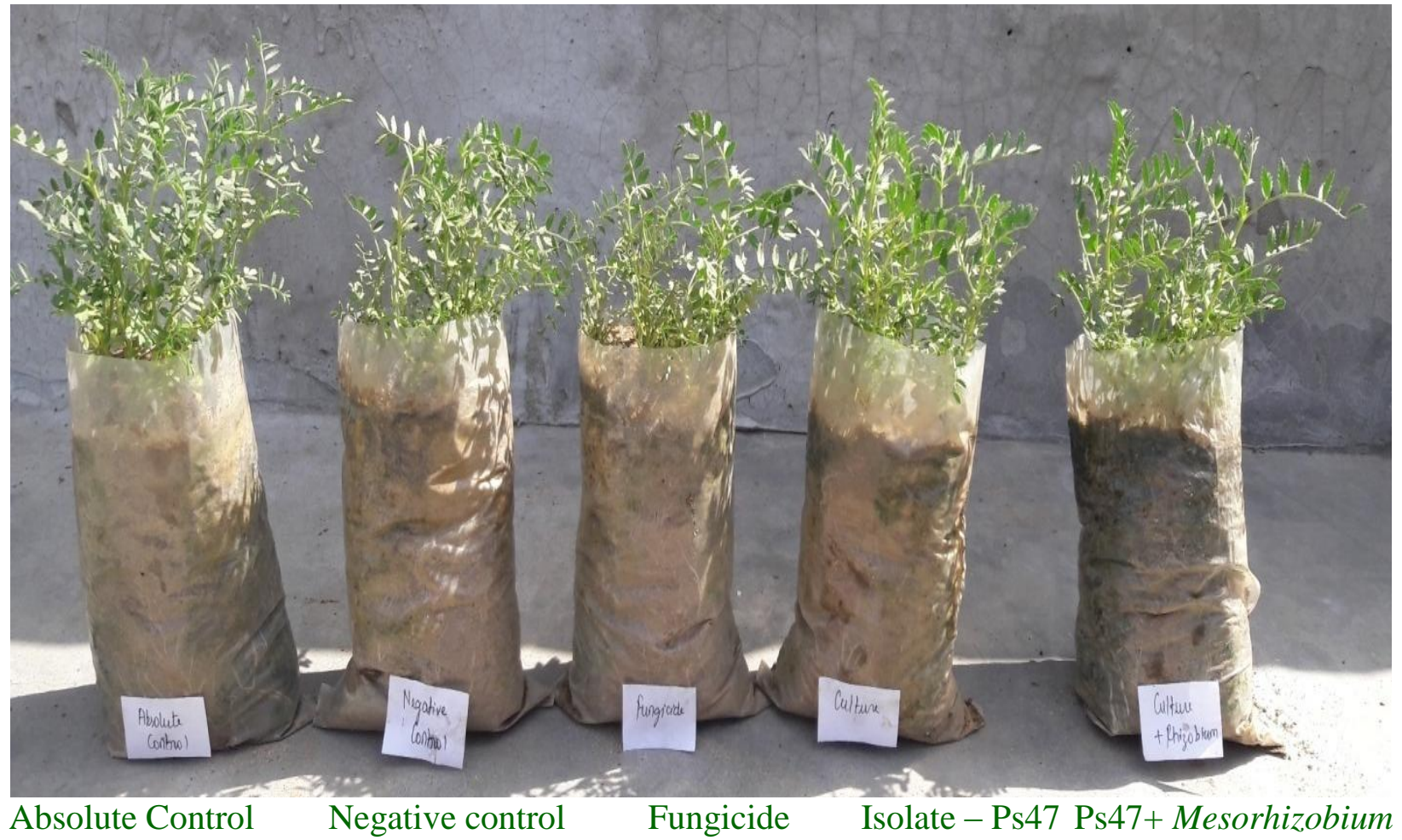

Plate.11 Symptoms of wilting in chickpea plants
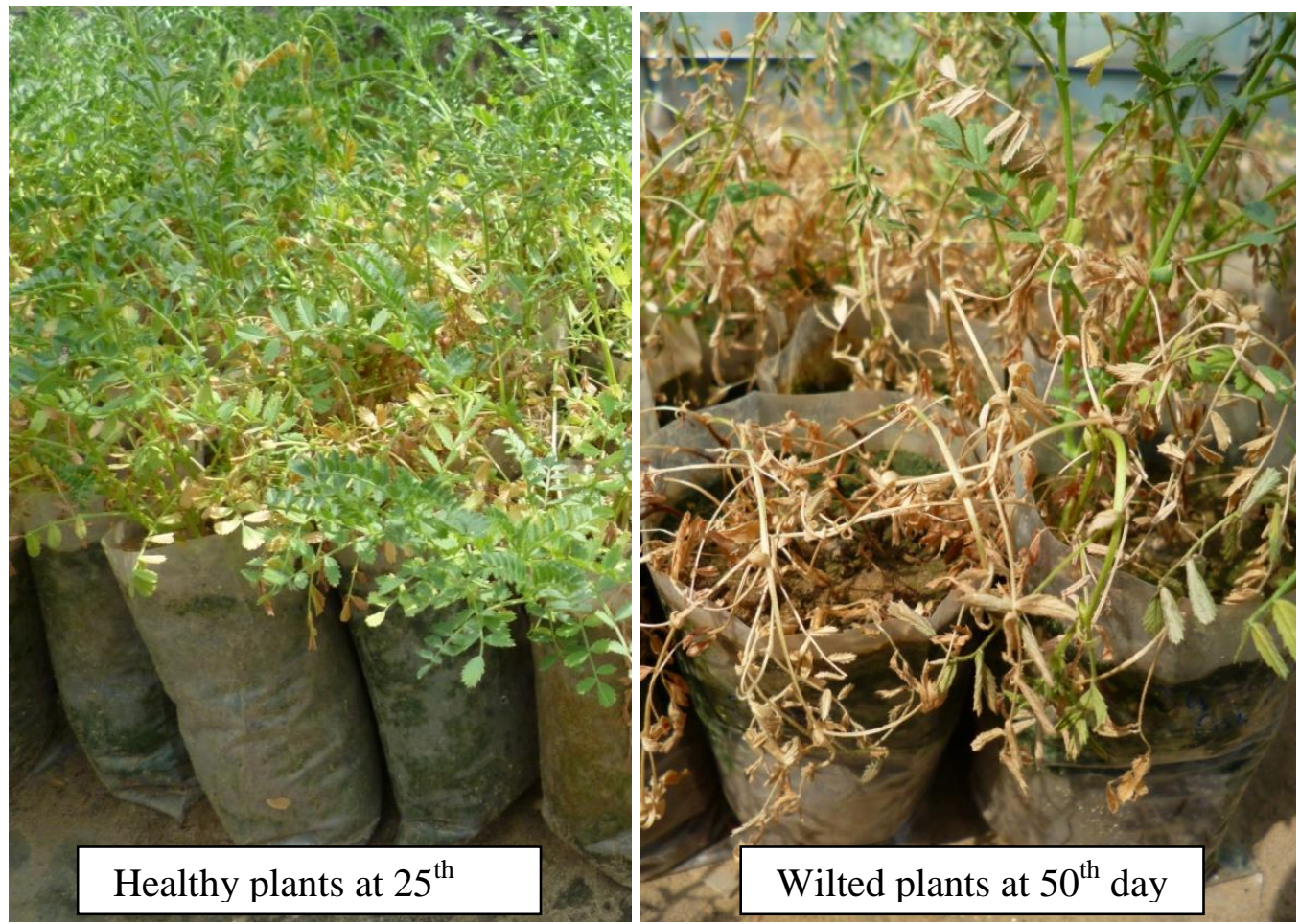
Plate.12 Relative wilt incidence in different treatments in chickpea under glass house conditions (GPF-2)

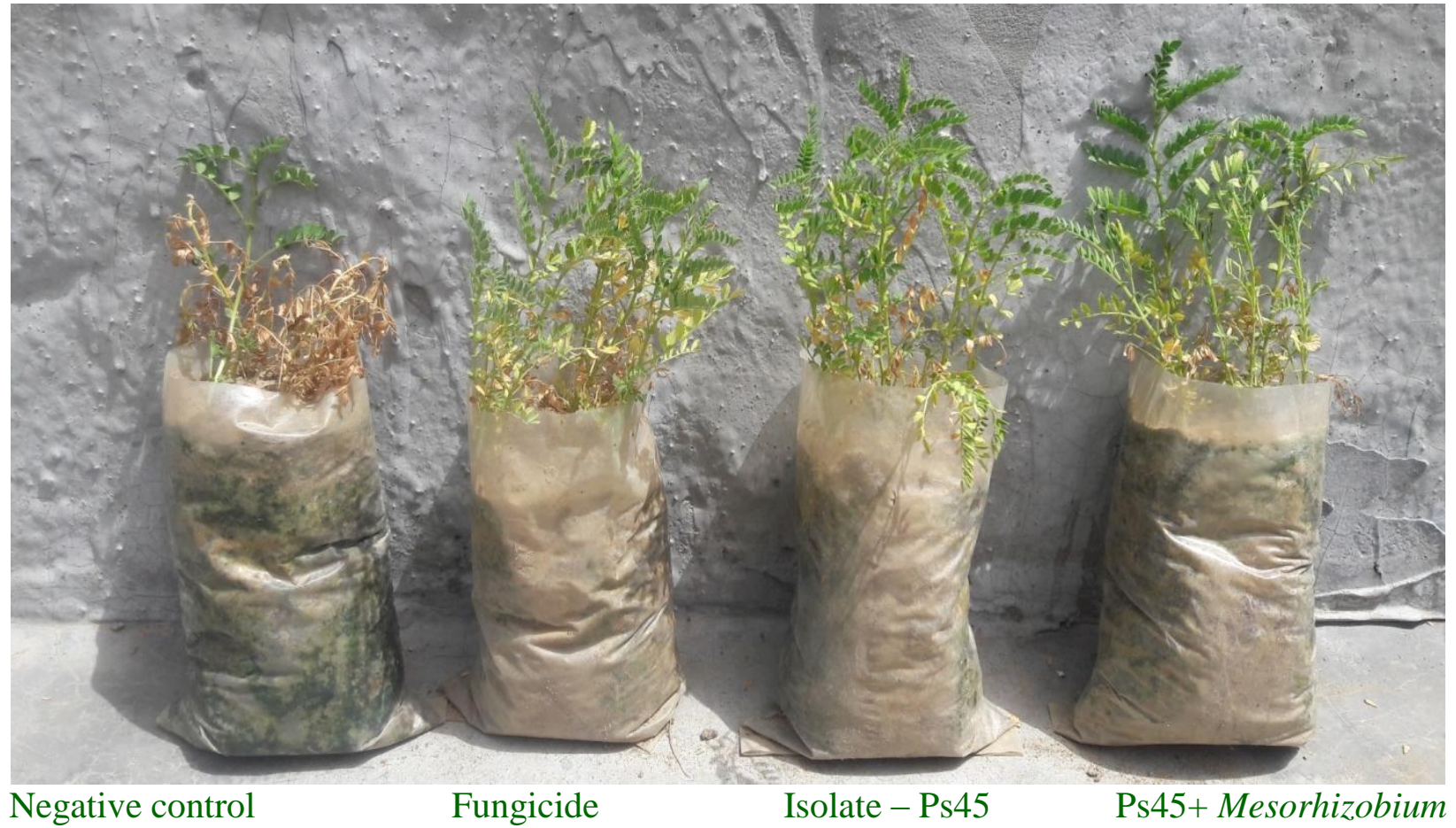

Plate.13 Relative wilt incidence in different treatments in chickpea under glass house conditions (JG-41)

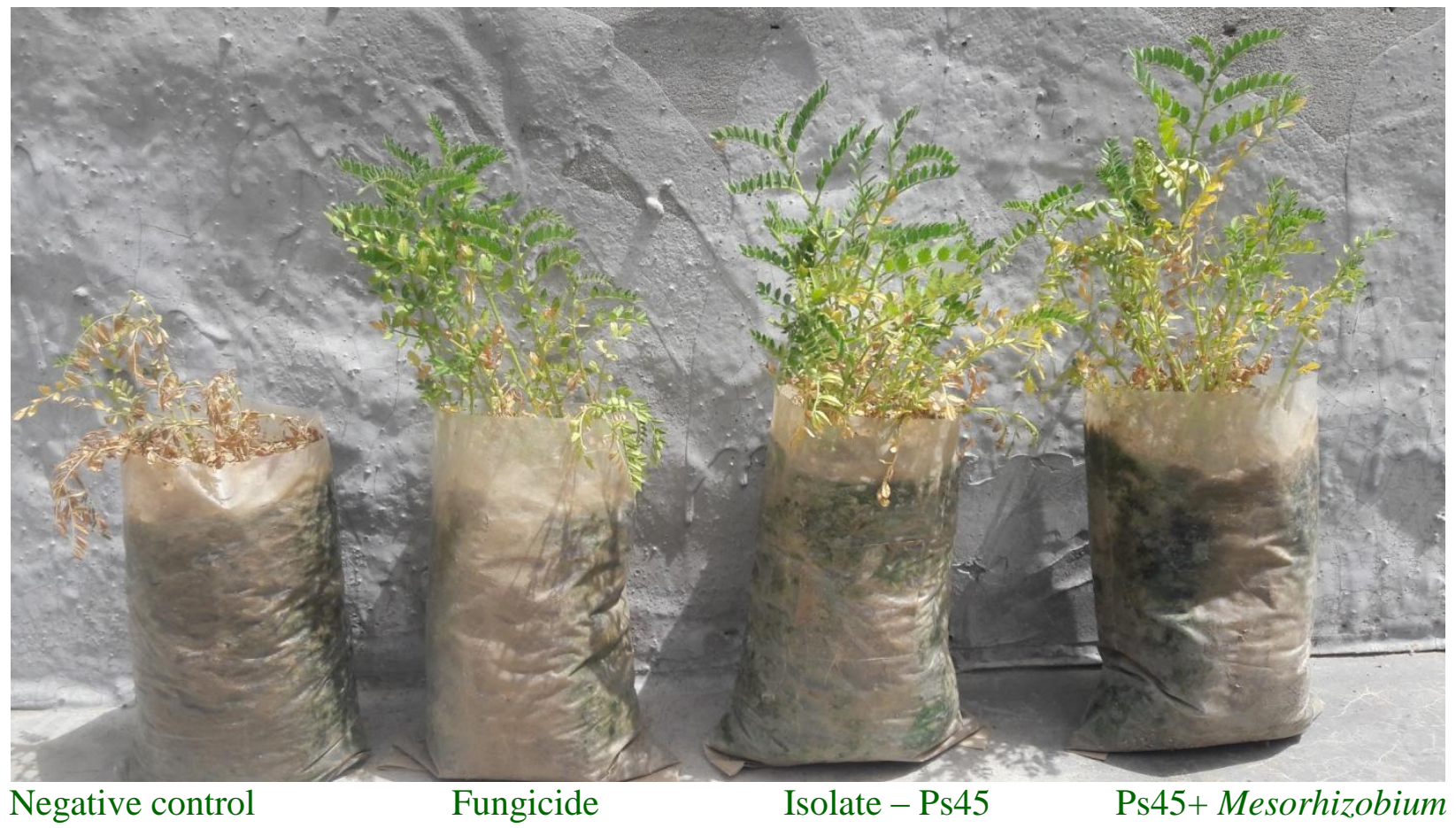


Table.1 Screening of rhizobacterial isolates against the radial growth of F. oxysporum f. sp. ciceris in dual culture technique

\begin{tabular}{|c|l|l|c|l|c|}
\hline $\begin{array}{c}\text { Serial } \\
\text { No. }\end{array}$ & Isolates & $\begin{array}{c}\text { \% Inhibition } \\
\text { over control }\end{array}$ & $\begin{array}{c}\text { Serial } \\
\text { No. }\end{array}$ & Isolates & $\begin{array}{c}\text { \% Inhibition } \\
\text { over control }\end{array}$ \\
\hline & Control & - & 31 & Ps8 & $37.1 \pm 1.06$ \\
\hline $\mathbf{1}$ & Ba1a & $40.0 \pm 0.67$ & 32 & Ps9 & $31.4 \pm 0.43$ \\
\hline $\mathbf{2}$ & Ba3 & $37.1 \pm 0.22$ & 33 & Ps10b & $40.0 \pm 1.19$ \\
\hline $\mathbf{3}$ & Ba4 & $40.0 \pm 0.05$ & 34 & Ps11 & $41.4 \pm 0.21$ \\
\hline $\mathbf{4}$ & Ba5 & $32.8 \pm 0.72$ & 35 & Ps12 & $31.4 \pm 0.76$ \\
\hline $\mathbf{5}$ & Ba7 & $32.8 \pm 0.21$ & 36 & Ps14 & $42.8 \pm 1.45$ \\
\hline $\mathbf{6}$ & Ba8 & $41.4 \pm 2.22$ & 37 & Ps15 & $38.5 \pm 0.62$ \\
\hline 7 & Ba10 & $41.4 \pm 1.19$ & 38 & Ps16b & $45.7 \pm 3.58$ \\
\hline $\mathbf{8}$ & Ba11 & $38.5 \pm 5.93$ & 39 & Ps17 & $32.8 \pm 0.67$ \\
\hline $\mathbf{9}$ & Ba13 & $35.7 \pm 0.61$ & 40 & Ps19 & $25.7 \pm 1.22$ \\
\hline $\mathbf{1 0}$ & Ba14 & $28.5 \pm 0.14$ & 41 & Ps20 & $35.7 \pm 0.59$ \\
\hline $\mathbf{1 1}$ & Ba15 & $40.0 \pm 0.05$ & 42 & PS21 & $42.8 \pm 0.90$ \\
\hline $\mathbf{1 2}$ & Ba17 & $38.5 \pm 0.62$ & 43 & Ps22 & $37.1 \pm 0.24$ \\
\hline $\mathbf{1 3}$ & Ba18 & $40.0 \pm 0.65$ & 44 & Ps24 & $40.0 \pm 0.30$ \\
\hline $\mathbf{1 4}$ & Ba19 & $40.0 \pm 0.74$ & 45 & Ps25 & $30.0 \pm 0.04$ \\
\hline $\mathbf{1 5}$ & Ba20 & $28.5 \pm 0.12$ & 46 & Ps26 & $41.4 \pm 0.08$ \\
\hline $\mathbf{1 6}$ & Ba21 & $28.5 \pm 0.11$ & 47 & Ps27 & $41.4 \pm 0.39$ \\
\hline $\mathbf{1 7}$ & Ba22 & $31.4 \pm 0.70$ & 48 & Ps31 & $35.7 \pm 0.29$ \\
\hline $\mathbf{1 8}$ & Ba24 & $38.5 \pm 0.35$ & 49 & Ps33 & $40.0 \pm 0.52$ \\
\hline $\mathbf{1 9}$ & Ba26 & $31.4 \pm 0.47$ & 50 & Ps35 & $28.5 \pm 0.32$ \\
\hline $\mathbf{2 0}$ & Ba27 & $40.0 \pm 0.16$ & 51 & Ps37 & $40.0 \pm 0.70$ \\
\hline $\mathbf{2 1}$ & Ba32 & $35.7 \pm 0.17$ & 52 & Ps38 & $30.0 \pm 0.16$ \\
\hline $\mathbf{2 2}$ & Ba34 & $28.5 \pm 0.67$ & 53 & Ps41 & $28.5 \pm 0.17$ \\
\hline $\mathbf{2 3}$ & Ba36 & $40.0 \pm 0.85$ & 54 & Ps42 & $38.5 \pm 0.38$ \\
\hline $\mathbf{2 4}$ & Ba42 & $34.2 \pm 0.21$ & 55 & Ps43 & $42.8 \pm 0.68$ \\
\hline $\mathbf{2 5}$ & Ps1 & $28.5 \pm 0.14$ & 56 & Ps44 & $42.8 \pm 0.22$ \\
\hline $\mathbf{2 6}$ & Ps2 & $31.4 \pm 0.21$ & 57 & Ps45 & $42.8 \pm 0.26$ \\
\hline $\mathbf{2 7}$ & Ps4 & $35.7 \pm 0.86$ & 58 & Ps46 & $31.4 \pm 0.18$ \\
\hline $\mathbf{2 8}$ & Ps5 & $38.5 \pm 0.60$ & 59 & Ps47 & $44.2 \pm 0.32$ \\
\hline $\mathbf{2 9}$ & Ps6 & $34.2 \pm 0.34$ & 60 & Sm1 & $31.4 \pm 0.80$ \\
\hline $\mathbf{3 0}$ & Ps7 & $28.5 \pm 1.16$ & 61 & Sm2 & $28.5 \pm 0.28$ \\
\hline & & & & \\
\hline
\end{tabular}


Table.2 Screenig of rhizobacterial isolates against the mycelial proliferation of F. oxysporum f. sp. ciceris in liquid medium

\begin{tabular}{|c|c|c|c|c|c|}
\hline $\begin{array}{l}\text { Serial } \\
\text { No. }\end{array}$ & Isolates & $\begin{array}{l}\% \text { Inhibition } \\
\text { over control }\end{array}$ & $\begin{array}{l}\text { Serial } \\
\text { No. }\end{array}$ & Isolates & $\begin{array}{l}\% \text { Inhibition } \\
\text { over control }\end{array}$ \\
\hline & Control & - & 31 & Ps8 & $64.4 \pm 0.12$ \\
\hline 1 & Bala & $83.0 \pm 0.22$ & 32 & Ps9 & $28.7 \pm 0.22$ \\
\hline 2 & $\mathrm{Ba} 3$ & $61.0 \pm 0.51$ & 33 & Ps10b & $61.0 \pm 0.91$ \\
\hline 3 & $\mathrm{Ba} 4$ & $73.6 \pm 0.92$ & 34 & Ps11 & $60.5 \pm 0.06$ \\
\hline 4 & Ba5 & $51.7 \pm 0.41$ & 35 & Ps12 & $30.0 \pm 1.70$ \\
\hline 5 & $\mathrm{Ba} 7$ & $63.1 \pm 0.91$ & 36 & Ps14 & $43.6 \pm 0.17$ \\
\hline 6 & $\mathrm{Ba} 8$ & $67.8 \pm 0.73$ & 37 & Ps 15 & $62.8 \pm 1.60$ \\
\hline 7 & Ba10 & $63.3 \pm 0.78$ & 38 & Ps16b & $69.7 \pm 1.17$ \\
\hline 8 & Ba11 & $64.4 \pm 6.93$ & 39 & Ps 17 & $35.6 \pm 11.8$ \\
\hline 9 & Ba13 & $28.7 \pm 0.15$ & 40 & Ps19 & $39.1 \pm 0.68$ \\
\hline 10 & Ba14 & $37.8 \pm 0.25$ & 41 & Ps20 & $51.7 \pm 0.05$ \\
\hline 11 & Ba15 & $50.6 \pm 1.27$ & 42 & PS21 & $55.3 \pm 0.14$ \\
\hline 12 & Ba17 & $63.1 \pm 1.55$ & 43 & Ps22 & $50.8 \pm 1.23$ \\
\hline 13 & Ba18 & $64.4 \pm 1.09$ & 44 & Ps24 & $49.4 \pm 1.45$ \\
\hline 14 & Ba19 & $78.5 \pm 0.11$ & 45 & Ps25 & $61.1 \pm 1.19$ \\
\hline 15 & $\mathrm{Ba} 20$ & $52.9 \pm 0.45$ & 46 & Ps26 & $67.4 \pm 1.25$ \\
\hline 16 & $\mathrm{Ba} 21$ & $51.7 \pm 0.38$ & 47 & Ps27 & $61.0 \pm 0.72$ \\
\hline 17 & $\mathrm{Ba} 22$ & $47.2 \pm 6.67$ & 48 & Ps31 & $28.7 \pm 0.13$ \\
\hline 18 & $\mathrm{Ba} 24$ & $50.1 \pm 1.14$ & 49 & Ps33 & $62.0 \pm 1.85$ \\
\hline 19 & $\mathrm{Ba} 26$ & $60.8 \pm 1.02$ & 50 & Ps35 & $50.4 \pm 1.38$ \\
\hline 20 & $\mathrm{Ba} 27$ & $63.1 \pm 1.39$ & 51 & Ps37 & $63.1 \pm 0.19$ \\
\hline 21 & Ba32 & $64.3 \pm 1.69$ & 52 & Ps38 & $54.1 \pm 0.16$ \\
\hline 22 & $\mathrm{Ba} 34$ & $59.9 \pm 2.40$ & 53 & Ps41 & $51.7 \pm 0.34$ \\
\hline 23 & $\mathrm{Ba} 36$ & $46.3 \pm 0.44$ & 54 & Ps42 & $50.6 \pm 1.95$ \\
\hline 24 & $\mathrm{Ba} 42$ & $26.4 \pm 0.72$ & 55 & Ps43 & $44.7 \pm 0.96$ \\
\hline 25 & Ps1 & $64.4 \pm 0.39$ & 56 & Ps44 & $86.2 \pm 0.84$ \\
\hline 26 & Ps2 & $40.3 \pm 0.22$ & 57 & Ps45 & $87.3 \pm 0.10$ \\
\hline 27 & Ps4 & $63.1 \pm 1.45$ & 58 & Ps46 & $52.9 \pm 1.31$ \\
\hline 28 & Ps5 & $61.0 \pm 1.21$ & 59 & Ps47 & $75.4 \pm 0.14$ \\
\hline 29 & Ps6 & $46.1 \pm 1.01$ & 60 & $\mathrm{Sm} 1$ & $28.7 \pm 0.46$ \\
\hline 30 & Ps7 & $63.1 \pm 0.197$ & 61 & $\mathrm{Sm} 2$ & $40.0 \pm 1.47$ \\
\hline
\end{tabular}


Table.3 Effect of rhizobacterial diffusible metabolites on suppression of the radial growth of F. oxysporum f. sp. ciceris.

\begin{tabular}{|c|c|c|c|c|c|c|c|}
\hline $\begin{array}{l}\text { Serial } \\
\text { No. }\end{array}$ & Isolates & $\begin{array}{c}\text { Diameter } \\
\text { of growth }(\mathrm{cm})\end{array}$ & $\begin{array}{l}\% \text { Inhibition } \\
\text { over control }\end{array}$ & $\begin{array}{l}\text { Serial } \\
\text { No. }\end{array}$ & Isolates & $\begin{array}{l}\text { Diameter of } \\
\text { growth }(\mathrm{cm})\end{array}$ & $\begin{array}{l}\% \text { Inhibition } \\
\text { over control }\end{array}$ \\
\hline & Control & 5.5 & - & & Control & 5.5 & - \\
\hline 1 & Bala & 1.8 & $67.2 \pm 0.06$ & 14 & Ps8 & 2.2 & $60.0 \pm 0.21$ \\
\hline 2 & $\mathrm{Ba} 4$ & 3.8 & $30.9 \pm 0.85$ & 15 & Ps10b & 0.5 & $90.9 \pm 0.25$ \\
\hline 3 & $\mathrm{Ba} 7$ & 4.0 & $27.2 \pm 0.65$ & 16 & Ps11 & 3.5 & $36.3 \pm 0.42$ \\
\hline 4 & $\mathrm{Ba} 8$ & 5.0 & $9.0 \pm 0.34$ & 17 & Ps14 & 1.2 & $78.1 \pm 030$ \\
\hline 5 & Ba10 & 4.3 & $21.8 \pm 0.59$ & 18 & Ps15 & 1.6 & $70.9 \pm 0.12$ \\
\hline 6 & Ba11 & 1.3 & $76.3 \pm 0.60$ & 19 & Ps16b & 1.4 & $74.5 \pm 1.31$ \\
\hline 7 & Ba17 & 1.9 & $65.4 \pm 0.18$ & 20 & Ps21 & 1.2 & $78.1 \pm 0.33$ \\
\hline 8 & Ba18 & 4.5 & $18.5 \pm 0.23$ & 21 & Ps33 & 4.8 & $12.7 \pm 1.81$ \\
\hline 9 & Ba19 & 1.4 & $74.5 \pm 0.21$ & 22 & Ps37 & 4.1 & $25.4 \pm 0.27$ \\
\hline 10 & $\mathrm{Ba} 27$ & 2.1 & $61.8 \pm 1.52$ & 23 & Ps43 & 2.0 & $63.6 \pm 0.16$ \\
\hline 11 & Ba32 & 2.0 & $63.6 \pm 0.95$ & 24 & Ps44 & 0.5 & $90.9 \pm 0.06$ \\
\hline 12 & Ps1 & 4.0 & $27.2 \pm 023$ & 25 & Ps45 & 0.5 & $90.9 \pm 0.26$ \\
\hline 13 & Ps5 & 4.0 & $27.2 \pm 0.28$ & 26 & Ps47 & 0.5 & $90.9 \pm 0.25$ \\
\hline
\end{tabular}

Table.4 Antagonistc effect of rhizobacterial volatiles on radial growth of Fusarium oxysporum f. sp. ciceris

\begin{tabular}{|c|c|c|c|c|c|c|c|}
\hline $\begin{array}{c}\text { Serial } \\
\text { No. }\end{array}$ & Isolates & $\begin{array}{l}\text { Diameter } \\
(\mathrm{cm})\end{array}$ & $\%$ Inhibition & $\begin{array}{c}\text { Serial } \\
\text { No. }\end{array}$ & Isolates & $\begin{array}{l}\text { Diameter } \\
(\mathrm{cm})\end{array}$ & $\%$ Inhibition \\
\hline & Control & 6.5 & - & & Control & 6.5 & - \\
\hline 1 & Bala & 2.0 & $56.0 \pm 0.30$ & 14 & Ps8 & 3.3 & $49.2 \pm 0.39$ \\
\hline 2 & $\mathrm{Ba} 4$ & 3.3 & $49.2 \pm 031$ & 15 & Ps10b & 3.3 & $49.2 \pm 0.62$ \\
\hline 3 & $\mathrm{Ba} 7$ & 3.0 & $53.8 \pm 0.27$ & 16 & Ps11 & 3.2 & $50.7 \pm 0.06$ \\
\hline 4 & $\mathrm{Ba} 8$ & 3.0 & $53.8 \pm 0.12$ & 17 & Ps 14 & 4.0 & $38.4 \pm 0.38$ \\
\hline 5 & Ba10 & 3.2 & $50.7 \pm 0.21$ & 18 & Ps 15 & 3.0 & $53.8 \pm 0.28$ \\
\hline 6 & Ba11 & 3.0 & $53.8 \pm 0.10$ & 19 & Ps $16 b$ & 4.5 & $30.7 \pm 0.24$ \\
\hline 7 & Ba17 & 3.3 & $49.2 \pm 0.01$ & 20 & Ps21 & 4.0 & $38.4 \pm 0.24$ \\
\hline 8 & Ba18 & 4.0 & $38.4 \pm 0.86$ & 21 & Ps33 & 3.3 & $49.2 \pm 0.19$ \\
\hline 9 & Ba19 & 2.5 & $53.8 \pm 0.19$ & 22 & Ps37 & 3.9 & $40.0 \pm 0.74$ \\
\hline 10 & $\mathrm{Ba} 27$ & 3.0 & $61.5 \pm 0.23$ & 23 & Ps 43 & 3.8 & $41.5 \pm 0.18$ \\
\hline 11 & $\mathrm{Ba} 32$ & 3.7 & $43.0 \pm 0.1$ & 24 & Ps 44 & 2.8 & $56.9 \pm 0.43$ \\
\hline 12 & Ps1 & 4.3 & $33.8 \pm 0.21$ & 25 & Ps 45 & 3.0 & $53.8 \pm 0.58$ \\
\hline 13 & Ps5 & 3.0 & $53.8 \pm 0.29$ & 26 & Ps47 & 0.6 & $90.7 \pm 0.68$ \\
\hline
\end{tabular}

Table.5 Evaluation of selected antagonists for the production of Hydrogen cyanide

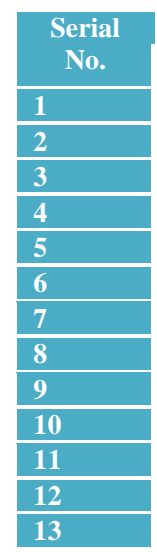

\begin{tabular}{|l|l|l|}
\hline \multirow{2}{*}{ Isolates } & \multicolumn{2}{|c|}{ HCN Production } \\
\cline { 2 - 3 } & \multicolumn{1}{|c|}{ Colour } & \multicolumn{1}{c|}{ Class } \\
\hline Ba1a & Orange-red & Moderate (++) \\
\hline Ba4 & Yellow-orange & Weak (+) \\
\hline Ba7 & & - \\
\hline Ba8 & & - \\
\hline Ba10 & & - \\
\hline Ba11 & & - \\
\hline Ba17 & Red & - \\
\hline Ba18 & & Strong (+++) \\
\hline Ba19 & & - \\
\hline Ba27 & Orange-red & Moderate (++) \\
\hline Ba32 & - & - \\
\hline Ps1 & & \\
\hline Ps5 &
\end{tabular}

\begin{tabular}{|l|}
\hline $\begin{array}{c}\text { Serial } \\
\text { No. }\end{array}$ \\
\hline 14 \\
\hline 15 \\
\hline 16 \\
\hline 17 \\
\hline 18 \\
\hline 19 \\
\hline 20 \\
\hline 21 \\
\hline 22 \\
\hline 23 \\
\hline 24 \\
\hline 25 \\
\hline 26 \\
\hline
\end{tabular}

\begin{tabular}{|l|l|l|}
\hline \multirow{2}{*}{ Isolates } & \multicolumn{2}{|c}{ HCN Production } \\
\cline { 2 - 3 } & \multicolumn{1}{|c}{ Colour } & \multicolumn{1}{c}{ Class } \\
\hline Ps8 & Orange-red & Moderate (++) \\
\hline Ps10b & & - \\
\hline Ps11 & Yellow-orange & Weak (+) \\
\hline Ps14 & & - \\
\hline Ps15 & & - \\
\hline Ps16b & & - \\
\hline Ps21 & & - \\
\hline Ps33 & & - \\
\hline Ps37 & & - \\
\hline Ps43 & & - \\
\hline Ps44 & Red & Strong (+++) \\
\hline Ps45 & Red & Strong (+++) \\
\hline Ps47 & Orange-red & Moderate (++) \\
\hline
\end{tabular}


Table.6 Ammonia production profile by selected antagonistic rhizobacteria

\begin{tabular}{|c|c|c|c|c|c|c|c|}
\hline \multirow{2}{*}{$\begin{array}{c}\text { Serial } \\
\text { No. }\end{array}$} & \multirow[t]{2}{*}{ Isolates } & \multicolumn{2}{|c|}{ Ammonia Production } & \multirow{2}{*}{$\begin{array}{c}\text { Serial } \\
\text { No. }\end{array}$} & \multirow[t]{2}{*}{ Isolates } & \multicolumn{2}{|c|}{ Ammonia Production } \\
\hline & & Colour & Class & & & Colour & Class \\
\hline 1 & Bala & Orange & ++ & 14 & Ps8 & Yellow-orange & + \\
\hline 2 & $\mathrm{Ba} 4$ & Orange-red & +++ & 15 & Ps $10 b$ & Orange & ++ \\
\hline 3 & $\mathrm{Ba} 7$ & Yellow-orange & + & 16 & Ps11 & Yellow-orange & + \\
\hline 4 & $\mathrm{Ba} 8$ & Yellow-orange & + & 17 & Ps 14 & Yellow-orange & + \\
\hline 5 & Ba10 & Yellow-orange & + & 18 & Ps 15 & Yellow-orange & + \\
\hline 6 & Ba11 & Orange-red & +++ & 19 & Ps 16b & Orange-red & +++ \\
\hline 7 & Ba17 & Orange & ++ & 20 & Ps21 & Orange-red & +++ \\
\hline 8 & Ba18 & Orange & ++ & 21 & Ps33 & Yellow-orange & + \\
\hline 9 & Ba19 & Orange & ++ & 22 & Ps37 & Orange-red & +++ \\
\hline 10 & $\mathrm{Ba} 27$ & Yellow-orange & + & 23 & Ps43 & Yellow-orange & + \\
\hline 11 & $\mathrm{Ba} 32$ & Orange-red & +++ & 24 & Ps44 & Orange & ++ \\
\hline 12 & Ps1 & Orange & ++ & 25 & Ps45 & Orange & ++ \\
\hline 13 & Ps5 & Yellow-orange & + & 26 & Ps47 & Orange-red & +++ \\
\hline
\end{tabular}

Weak $=+$, Moderate $=++$, Strong $=+++$

Table.7 Impact of potential antagonists alone and alongside Mesorhizobium on germination index of two chickpea varieties (GPF-2 and JG-41) under glass house conditions

\begin{tabular}{|c|c|c|c|}
\hline \multirow[t]{2}{*}{ Serial No. } & \multirow[t]{2}{*}{ Treatments } & \multicolumn{2}{|c|}{ Seedling emergence $(\%)$} \\
\hline & & GPF-2 & JG-41 \\
\hline 1 & Absolute control & $86.7 \pm 1.33$ & $73.3 \pm 1.76$ \\
\hline 2 & Negative control & $66.6 \pm 0.33$ & $63.4 \pm 0.89$ \\
\hline 3 & Fungicide (Captan) & $86.6 \pm 1.30$ & $76.6 \pm 1.20$ \\
\hline 4 & Ps44 & $77.0 \pm 1.20$ & $80.0 \pm 1.15$ \\
\hline 5 & Ps45 & $86.6 \pm 0.88$ & $73.3 \pm 1.33$ \\
\hline 6 & Ps47 & $83.3 \pm 1.67$ & $80.0 \pm 1.52$ \\
\hline 7 & Ba19 & $76.7 \pm 1.22$ & $74.1 \pm 1.77$ \\
\hline 8 & Ba1a & $73.3 \pm 1.45$ & $76.6 \pm 1.20$ \\
\hline 9 & Ps44+Mesorhizobium & $80.0 \pm 1.00$ & $83.0 \pm 1.20$ \\
\hline 10 & Ps45+Mesorhizobium & $93.3 \pm 0.66$ & $80.0 \pm 1.15$ \\
\hline 11 & Ps47+Mesorhizobim & $90.0 \pm 1.00$ & $86.7 \pm 1.33$ \\
\hline 12 & Ba19+Mesorhizobium & $83.3 \pm 1.67$ & $83.3 \pm 1.20$ \\
\hline 13 & Ba1a + Mesorhizobium & $86.7 \pm 0.89$ & $76.7 \pm 0.88$ \\
\hline 14 & C.D. at $5 \%$ & NS & NS \\
\hline
\end{tabular}

Table.8 Reduction of wilt severity by antagonistic rhizobacteria in chickpea varieties (GPF-2 and JG-41) under pot conditions

\begin{tabular}{|c|c|c|c|}
\hline \multirow[t]{2}{*}{ Serial No. } & \multirow[t]{2}{*}{ Treatments } & \multicolumn{2}{|c|}{ Reduction in disease severity $(\%)$} \\
\hline & & GPF-2 & JG-41 \\
\hline 1 & Absolute control & $61.50 \pm 0.33$ & $67.61 \pm 0.57$ \\
\hline 3 & Fungicide (Captan) & $61.53 \pm 0.89$ & $58.69 \pm 0.33$ \\
\hline 4 & Ps44 & $62.73 \pm 0.67$ & $60.42 \pm 0.33$ \\
\hline 5 & Ps45 & $67.03 \pm 0.58$ & $56.81 \pm 0.33$ \\
\hline 6 & Ps47 & $65.52 \pm 0.57$ & $55.46 \pm 0.33$ \\
\hline 7 & Ba19 & $56.52 \pm 1.00$ & $46.01 \pm 0.57$ \\
\hline 8 & Bala & $61.03 \pm 0.69$ & $58.69 \pm 0.33$ \\
\hline 9 & Ps44+Mesorhizobium & $64.28 \pm 0.55$ & $66.74 \pm 0.66$ \\
\hline 10 & Ps45+Mesorhizobium & $74.48 \pm 0.67$ & $70.32 \pm 1.00$ \\
\hline 11 & Ps47+Mesorhizobim & $73.54 \pm 0.66$ & $68.02 \pm 0.66$ \\
\hline 12 & Ba19+Mesorhizobium & $65.71 \pm 1.15$ & $57.20 \pm 0.00$ \\
\hline 13 & Bala +Mesorhizobium & $72.52 \pm 0.68$ & $63.80 \pm 0.66$ \\
\hline 14 & C.D. at $5 \%$ & NS & 1.54 \\
\hline
\end{tabular}


Elucidation of antagonistic mechanism via hydrogen cyanide and ammonia production

Hydrogen cyanide and ammonia belong to volatile antifungal metabolites and play a very important role in inhibiting the spore germination and mycelia growth of various fungal phytopathogens (Fernando et al., 2005). All the isolates were found to produce ammonia supported by one of our earlier reports (Kumari and Khanna, 2014) (Plate 5). Seven (26.9 \%), Eight (30.7\%) and eleven $(42.30 \%)$ were found to be strong, moderate and weak ammonia producer (Table 6). However only nine (34\%) isolates were found positive for hydrogen cyanide production out of which $22.2 \%$ were weak, 44.4 moderate and $33.3 \%$ were strong $\mathrm{HCN}$ producers on the basis of intensity of colour (yellow/yellowishorange/orange-red) produced (Table 5, Plate 6). In addition to Bacillus and Pseudomonas spp. reports are there that Mesorhizobium spp. also produce $\mathrm{HCN}$, and ammonia along with some enzymes like catalase, chitinase etc (Ahemad and Khan 2009). Ammonia inhibits cell cycle progression and thus inhibits the bacterial progression whereas Hydrogen cyanide produced by these antagonistic rhizobacteria mainly affects the respiratory chain i.e. electron transport chain of the pathogens and thus makes them ATP deficient for further growth and development. In support to this, Guo et al., (2007) reported that the release of $\mathrm{HCN}$ by rhizospheric bacteria into the soil can be toxic to subterranean animals and phytopathogenic organisms and thus is an important mechanism in biological control of soil borne pathogens.

\section{Other plant growth promoting traits}

Five potent antagonists (Ba1a, Ba19, Ps44, Ps45 and Ps47) were selected on the basis of intensity of antagonistic traits to inhibit the growth of Fusarium oxysporum f. sp. ciceris (Foc) in laboratory conditions. These 5 selected antagonists were also evaluated for their efficiency to produce various plant growth promoting metabolites. All the isolates were found positive for the production of plant growth hormones such as Indole acetic acid (IAA), Gibberellic acid and iron chelating agent, siderophores as their excretions. Studies revealed that plant growth hormones like gibberellins, IAA and cytokinin play important role in bacterial plant interactions (Dobbelaere et al., 2003). Further they were also found efficient in Zinc and Phosphate solublization (Plate 7), indicating the production and release of various organic acids responsible for the nutrient solublization, one of the mechanisms by which plant growth promoting rhizobacteria deprive the pathogen from these essential nutrients and enhance the nutrient availability to the plants (Castagno et al., 2011).

\section{Compatibility test}

Rhizobacterial antagonists were evaluated for their compatibility with Mesorhizobium, (recommended culture of Department of Microbiology), specific for chickpea. The overlapping growth to each other on Yeast Mannitol agar plates was determined as compatible interaction between the paired microorganisms. All the antagonists showed positive interaction with Mesorhizobium indicating, their synergistic influence on plant growth promoting performance.

Impact of adversarial rhizobacteria alone and alongside local Mesorhizobium, on seedling development of chickpea

A pot experiment was conducted to evaluate the effect of potent antagonists to control wilt and enhance the growth parameters of chickpea (Plate 8). Three Pseudomonas 
(Ps44, Ps45 nad Ps47) and two Bacillus (Ba1a and Ba19) antagonists selected on the basis of antagonistic parameters alone and alongside local Mesorhizobium, along with Captan ( $2 \mathrm{~g} / \mathrm{Kg}$ seeds) as a separate treatment were observed for their impact on the seed germination of two chickpea varieties (GPF-2 and JG41), compared to negative control, under glass house conditions. Observations revealed that highest seedling emergence was recorded in case of treatments of antagonists along with Mesorhizobium, indicating the synergistic effect to enhance the seed development (Table 7). Seed bacterization with Ps45 induced maximum germination, followed by Ps 47 and Bala co-inoculated with Mesorhizobium compared to Captan and negative control in GPF-2 variety (Table 7, Plate 9).

Similarly in case of JG-41, co-inoculation with Mesorhizobium was recorded with maximum seedling growth by Ps47 86.7\%, followed by Ba19, Ps44 and Ps45 (Table 7, Plate 10). Co-inoculation with Mesorhizobium was recorded with positive influence on germination compared to negative control and even was found better than the fungicide, indicating the adverse effect of chemical fungicide on germination (in sterile soil containing no beneficial microbes) (Plate 9, 10).

Similar results were recorded by Kumari and Khanna in 2014. Effectively rhizobacterial seed treatment recorded percentage germination of tomato seeds in the range between 83.33 to $100 \%$ in contrast to $75 \%$ noted on the untreated control ones in Sclerotinia sclerotiorum affected soil under pot conditions (Abdeljalil et al., 2016). Landa and his co-workers also reported that Pseudomonas fluorescens RG Bacillus megaterium RGAF enhanced seedling emergence compared to negative control (Landa et al., 2004).

\section{Elucidation of antiphytopathogenic potential to reduce disease severity in chickpea}

Wilt symptoms started after 30 days of sowing, with drooping, decoloured leaves and plants became almost dry and dead in negative control after 50 days (Plate 11). Same as the seed growth, wilt incidence was noticeably reduced by rhizobacterial isolates co-inoculated with Mesorhizobium. Percentage disease reduction was recorded by taking total wilt in negative control as standard. Observations revealed that even absolute control containing normal non sterile soil of the field having the history of chickpea cultivation, also showed wilt symptoms. Seed treatment with Ps45+Mesorhizobium was recorded with maximum reduction in disease i.e. $74.48 \pm 0.67 \%$ followed by Ps47+Mesorhizobium 73.54 \pm 0.66 , and Ba1a + Mesorhizobium $72.52 \pm 0.68 \%$, compared to fungicide treatment $61.53 \pm 0.89 \%$ in variety GPF-2 (Plate 12). Relevantly In JG-41, Ps45+Mesorhizobium application to the seeds showed minimum wilt incidence, with percentage reduction in disease of $70.32 \pm 1.00 \%$ and treatment of Ps47+Mesorhizobium reduced the disease $68.02 \pm 0.66 \%$, compared to concision effect of fungicide $(58.69 \pm 0.33 \%)$ (Table 8, Plate 13). In a similar report, Pf1-Bs16 and Pf1-Py15 recorded disease severity of 16.66 and $24.99 \%$ disease incidence and reduced the disease $(81.8 \%)$ and $(72.7 \%)$, respectively against $91.63 \%$ disease incidence in control in mulburry (Ganeshamoorthi et al., 2008). Efficacy to descend the disease by rhizobacterial treatment is not only limited to wilt, but these are also effective against other diseases such as, root rot by Rhizoctonia solani stem rot caused by Sclerotinia sclerotiorum, damping off by Phytophthora spp. etc by various antagonist mechanisms (Yang et al., 2009). The highest disease incidence $(100 \%)$ was noted on tomato plants 
inoculated with $S$. Sclerotiorum in control where treatment using $B$. thuringiensis B2 (KU158884), B. subtilis B10 (KT921327), B. amyloliquefaciens B13 (KT951658), $B$. amyloliquefaciens B15 (KT923051), and E. cloacae B16 (KT921429) led to total suppression of disease development and using 8 out of the 25 strains tested, disease incidence did not exceeded $20 \%$ as compared to $100 \%$ recorded on pathogen-inoculated and untreated control (Abdeljalil et al., 2016). All these studies emphasize on the effective role of plant growth promoting rhizobacteria to control wide range of pathogens, by various antagonistic mechanisms, so as to reduce the disease severity and enhance the germination, growth and thus yield of economically important crops.

With increasing awareness about the adverse effects of chemical fertilizers and pesticides, it is very important to explore various mechanisms by which plant growth promoting rhizobacteria can control the phytopathogenic effects in the crop plants.

In our study screened antagonistic isolates alone were also efficient in contrast to control but co-inoculation with Mesorhizobium has given better results in enhancing the seed germintion and controlling the wilt incidence caused by Fusarium oxysporum f. sp. ciceris in both the chickpea varieties (GPF-2 and JG41) under glass house controlled conditions against the negative control and fungicide treatment.

They could be used as biofungicides on the condition of their similar effectiveness under field conditions. Further investigations are focussed to even enhance the self defence mechanism of plants by these antagonistic rhizobacteria and to evaluate the synergistic potential of antagonists to formulate various combinations of these so as to have better results against these phytopathogens.

\section{Acknowledgments}

The present investigation was conducted in the Pulses section, Department of Plant Breeding and Genetics, Punjab Agricultural University. Further support and assistance was provided by Department of Microbiology, Punjab Agricultural University, Ludhiana, Punjab and Department of Science and technology, New Delhi, India.

\section{References}

Abdeljalil, N.O.B., Vallance, J., Gerbore, J., Rey, P., and Remadi M.D. 2016. Biosuppression of Sclerotinia Stem Rot of Tomato and Biostimulation of Plant Growth Using Tomato associated Rhizobacteria. J. Pl. Pathol Microbiol. 7(2): 1-11.

Ahemad, M., and Khanm, M. S. 2009. Effect of Insecticide-Tolerant and Plant Growth-Promoting Mesorhizobium on the Performance of Chickpea Grown in Insecticide Stressed Alluvial Soils. J. Crop. Sci. Biotech. 2(4): 217- 226.

Ahmed, Idris, H., Labuschagne, N., and Korsten, L. 2007. Screening rhizobacteria for biological control of Fusarium root and crown rot of sorghum in Ethiopia. Biol. control. 40: 97- 106.

Aktar, M.W., Sengupta, D., Chowdhuri, A. 2009. Impact of pesticides use in agriculture: their benefits and hazards. Interdisc Toxicol. 2(1): 1-12.

Altinok, H. H., Dikilitas, and M. Yildiz, H. N. 2014. Potential of Pseudomonas and Bacillus Isolates as Biocontrol Agents against Fusarium Wilt of Eggplant. Biotechnol. and Biotechnol. 47: 295258.

Anonymous, 2015. Commodity profile of pulses - March 2015. Department of Agriculture and Co-operation, Ministry of Agriculture, Government of India. 
Arias, A.A., Ongena, M., Halimi, B., Lara, Y., and Brans, A. 2009. Bacillus amyloliquefaciens GA1 as a source of potent antibiotics and other secondary metabolites for biocontrol of plant pathogens. Microb. Cell Fact. 8: 63-70.

Bakker, A. W., and Schippers, B. 1987. Microbial cyanide production in the rhizosphere in relation to potato yield reduction and Pseudomonas spp. mediated plant growth stimulation. Soil Biol. Biochem. 19: 249-256.

Borrow, A., P., W, Brain, U., E., Chester, P,.J. Curtis, H., G., Hemming, E., C, Jeffereys, R., B., Lloyd, I., S., Nixon, G., L., F., Norris, and N., Radley. 1955. Gibberellic acids a metabolic product of the fungus Gibberella fujikuroi some observations on its production and isolation. J. Sci. Food. Agric. 6: 340348.

Butler, E.J., 1918. Fungi and Diseases in Plants. Thacker Spink and Co., Calcutta, India, 547pp.

Cappuccino J. C. and Sherman, N. 1992. In: Microbiology: A Laboratory Manual, New York. Academic distributors, New Delhi. pp. 125-179.

Castagno L.N., Estrella, M.J., Sannazzaro, A.I., Grassano, A.E., and Ruiz, O.A. 2011. Phosphate solubilization mechanism and in vitro plant growth promotion activity mediated by Pantoea eucalypti isolated from Lotus tenuis rhizosphere in the Salado River Basin (Argentina). J. Appl. Microbiol. 110: 1151- 1165.

Deshwal, V.K, Pandey, P., Kang, K.C., and Maheshwari, D.K. 2003. Rhizobia as biological control against soil-borne plant pathogenic fungi. Ind. J. Exp. Biol. 41: 1160-1164.

Dobbelaere, S.J., Vanderleyden, and Okon, Y. 2003. Plant growthpromoting effects of diazotrophs in the rhizosphere. Crit. Rev. Plant Sci. 22: 107-149.
Dubey, S.C., Singh, and Birendra 2004. Reaction of chickpea genotypes against Fusarium oxysporum f. sp. ciceri causing vascular wilt. Indian Phytopath. 57: 233-237.

Edi Premono M., Moawad A. M., and Vlek P. L. G. 1996. Effect of phosphatesolubilizing Pseudomonas putida on the growth of maize and its survival in the rhizosphere. Indones. J. Crop Sci. 11: 13-23.

Ehmann, A., 1977. The Van Urk-Salkowski reagent-a sensitive and specific chromogenic reagent for silica gel thinlayer chromatographic detection and identification of indole derivatives. $J$. Chromatogr. 132: 267-276.

Fernando, W.G.D., Ramarathan, R., Krishnamoorthy, A.S., and Savchuk, S.C. 2005. Identification and use of potential bacteria organic antifungal volatile isolates in biocontrol. Soil Biol. Biochem. 37: 955-964.

Fiddman, P. J. and Rossall. S. 1993. The production of antifungal volatiles by Bacillus subtilis. J Appl Bacteriol 74:119-126.

Ganeshamoorthi, P., Anand, T., Prakasam, V., Bharani, M., Ragupathi, and Samiyappan, R. N. 2008. Plant growth promoting rhizobacterial (PGPR) bioconsortia mediates induction of defense-related proteins against infection of root rot pathogen in mulberry plants. J. Pl. Interactions. 3: 233-244.

Giorgio, A., Stradis, A.D., Cantore, P.L., and Lacobellis, N.S. 2015. Biocide effects of volatile organic compounds produced by potential biocontrol rhizobacteria on Sclerotinia sclerotiorum. Front Microbiol. 6: 1-13.

Gopalakrishnan, S., Pande, S., Sharma, M., Humayun, P., Kiran, B.K., Sandeep, D. Vidya, Deepthi, M. S.K., Rupela, O. 2011. Evaluation of actinomycete 
isolates obtained from herbal vermicompost for the biological control of Fusarium wilt of chickpea. Crop Prot. 30: 1070-1078.

Guo, Y., Zheng, H., Yang, Y. Wang, H. 2007. Characterization of Pseudomonas corrugate strain P94 isolated from soil in Beijing as a potential biocontrol agent. Curr. Microbiol. 55: 247-53.

Hossain, M.M., Hossain, N., Sultana, F., Islam, S.M.N., Islam, M.S. Bhuiyan, M.K.A. 2013. Integrated management of Fusarium wilt of chickpea (Cicer arietinum L.) caused by Fusarium oxysporum f. sp. ciceris with microbial antagonist, botanical extract and fungicide. Afr. J. Microbiol. 12(29): 4699-4706.

Isnansetyo, A., Cui, L., Hiramatsu, and Kamei, K.Y. 2003. Antibacterial activity of 2,4 diacetylphloroglucinol (DAPG) produced by Pseudomonas sp. AMSN isolatsed from a marine alga, against

vancomycin-resistant Staphylococcus aureus (VRSA). Int. J. Antimicrob. Agents 22: 545-547.

Kai, M., Effmert, U., Berg, G., and Piechulla, B. 2007. Volatiles of bacterial antagonists inhibit mycelial growth of the plant pathogen Rhizoctonia solani. Arch. Microbiol. 187: 351-360.

Karnwal, A., Kumar, V. 2012. Influence of plant growth promoting rhizobacteria (pgpr) on the growth of chickpea (Cicer arietinum L.). Ann Food Sci. Tech. 13(2): 1-6.

King, E.O., Ward, M.K. Raney, D.E. 1954.

Two simple media for the demonstration of pyocyanin and fluorecein. J. Lab. Clin. Med. 44: 30107.

Kravchenko, L.V., Makarova, N.M., Azarova, T.S., Provorov, N.A. and Tikhonovich, I.A. 2002. Isolation and phenotypic characteristics of growth-stimulating rhizobacteria (PGPR), with high root- colonizing and phytopathogenic fungi inhibiting abilities. Microbiol. 71(4): 521-525.

Kumar, H., Bajpai, V. K., Dubey, R.C., Maheshwari, D.K., and Kang. S.C., 2010. Wilt disease management and enhancement of growth and yield of Cajanus cajan (L) var. Manak by bacterial combinations amended with chemical fertilizer. Crop Prot. 29: 591598.

Kumari, S. and Khanna, V. 2014. Effect of antagonistic rhizobacteria coinoculated with Mesorhizobium ciceris on control of fusarium wilt in chickpea (Cicer arietinum L.). Afr. J. Micro. Res. 8(12): 1255- 1265.

Landa, B.B., Cortés, J.A.N., Díaz, R.M.J. 2004. Influence of temperature on plant-rhizobacteria interactions related to biocontrol potential for suppression of fusarium wilt of chickpea. Pl. Pathol. 53: 341-352.

Meki, S., Ahmed S. and Sakhuja P.K. 2009. Control of chickpea wilt (Fusarium oxysporum f.sp. ciceris) using Trichoderma spp. in Ethiopia. Arch. Phytopathol. Pl. Protec. 44, 5.

Merkuz A., and Getachew, A. 2012. Distribution and severity of sorghum covered kernel smut in North western Ethiopia. Int. J. Curr. Res. 4 (4): 41-45.

Merkuz A., Seid A., Chemeda F., Sakhuja P.K. and Getachew A. 2011. Effect of mustard green manure and driedplant residue on chickpea wilt (Fusarium oxysporum f.sp. ciceris). Arch. Phytopathol. Pl. Protec. 44 (9), 821 831.

Moradi, H., Bahramnejad, B., Amini, Siosemarde, A., and Allahverdipoor, K.H. 2012. Suppression of chickpea (Cicer arietinum L.) Fusarium wilt by Bacillus subtillis and Trichoderma harzianum. Pl. Omics J. 5(2): 68-74.

Nautiyal, C.S., 2000. Biocontrol of plant 
diseases for agricultural sustainability. In: Upadhyay R.R., Mukerji K.G., Chamola B.P., (eds.), Biocontrol potential and its exploitation in sustainable agriculture, Volume 1. Crop Diseases, Weeds, and Nematodes. Kluwer Academy Plenum, New York. pp. 9-23.

Pande, S, Desai, S., Sharma, M. 2010. Impacts of climate change on rainfed crop diseases: Current Status and Future Research Needs. National Symposium on Climate Change and Rainfed Agriculture, Hyderabad. 18(20): 55-59.

Prashar P., N. Kapoor, Sachdeva, S. 2013. Isolation and Characterization of Bacillus sp with In-vitro Antagonistic Activity against Fusarium oxysporum from Rhizosphere of Tomato. Agr. Sci. Tech. 15:1501-12.

Reino, L.R, Raul, F., Herna'ndez-Gala'n, G.R., Collado, I.G. 2008. Secondary metabolites from species of the biocontrol agent Trichoderma. Phytochem. Rev. 7: 89-123.

Ryan, R.P., Fouhy, Y., and Garcia, B.F. 2008. Interspecies signaling via the Stenotrophomonas maltophilia diffusible signal factor influences biofilm formation and polymyxin tolerance in Pseudomonas aeruginosa. Mol. Microbiol. 68: 75-86.

SchwynB and Neilands J B, 1987. Universal chemical assay for detection and determination of siderophore. Anal. Biochem. p. 47.

Vesperman A, Kai, M., and Piechulla, B. 2007. Rhizobial volatiles affect the growth of fungi and Arabidopsis thaliana. Appl. Environ. Microbiol. 73: 5639-5641.

Yang, J., Kloepper, J.W., and Ryu, C.M. 2009. Rhizosphere bacteria help plants tolerate abiotic stress. Trends. Plant. Sci. 14: 1-4.

\section{How to cite this article:}

Suman Kumari and Veena Khanna. 2018. Biological Management of Vascular Wilt of Chickpea (Cicer arietinum L.) Incited by Fusarium oxysporum $f$. sp. ciceris by Antagonistic Rhizobacteria Co-Inoculated with Native Mesorhizobium. Int.J.Curr.Microbiol.App.Sci. 7(01): 920-941. doi: https://doi.org/10.20546/ijcmas.2018.701.112 